\title{
A QUESTÃO DA REPRESENTAÇÃO NO MERCOSUL: OS CASOS DO PARLASULE DO FCCR ${ }^{1}$
}

\author{
Marcelo de \\ Almeida \\ Medeiros
}

\author{
Natália \\ Leitão
}

\author{
Henrique \\ Sérgio
}

Cavalcanti

\author{
Maria \\ Eduarda Paiva
}

Rodrigo

Santiago

\section{RESUMO}

Um dos problemas que mais têm chamado a atenção dos estudiosos das organizações regionais internacionais (ORI) é o da representação. Os arranjos institucionais nelas edificados têm procurado refletir essa representação em sua dupla vertente, a saber: uma assembléia constituída pelos estados-membros; outra formada por delegados dos cidadãos. Alguns deles, todavia, têm inovado por meio da criação de fóruns compostos por entes subnacionais, a fim de procurar atenuar o que certos autores têm denominado de "déficit democrático". O objetivo deste trabalho é escrutar a dinâmica constitutiva de dois órgãos de representação do Mercado Comum do Sul: (i) o Parlamento do Mercosul (Parlasul) e (ii) o Foro Consultivo de Municipios, Estados Federados, Províncias e Departamentos do Mercosul (FCCR). Procura-se identificar os parâmetros que balizam as suas respectivas composições e, a partir daí, tenta-se pensar a questão da representação. A conclusão é de que apesar dos papéis essencialmente consultivos do Parlasul e do FCCR e de suas imperfeições no que concerne à prática da representação e do controle, elas constituem-se em elementos concretos que podem, ou não, gerar momentum para novas invenções políticas.

PALAVRAS-CHAVE: Mercosul; representação; Parlamento; paradiplomacia; regionalismo.

\footnotetext{
"The Euro-polity in its present, provisional configuration is not a democracy and will not become one unless and until its member states decide explicitly to endow it with new rules and rights" (SCHMITTER, 2000, p. 2). ${ }^{2}$
}

\section{INTRODUÇÃO}

Um dos problemas que mais tem chamado atenção dos estudiosos das organizações regionais internacionais (ORIs) é o da representação. Os arranjos institucionais nelas edificados têm procurado refletir essa representação em sua dupla vertente, a saber: uma assembléia constituída pelos estados-membros; outra formada por delegados dos cidadãos. Alguns deles, todavia, têm inovado por meio da criação de fora compostos por entes subnacionais que, na verdade, procuram atenuar o que certos autores têm denominado de "déficit democrático". O objetivo deste trabalho é escrutar a dinâmica constitutiva de dois órgãos

\footnotetext{
1 Este trabalho foi financiado pelo Conselho Nacional de Desenvolvimento Científico e Tecnológico (CNPq), por meio de Bolsa de Produtividade em Pesquisa, Bolsa de Mestrado e Programa Institucional de Bolsas de Iniciação Científica (PIBIC).
}

de representação do Mercado Comum do Sul: o Parlamento do Mercosul (Parlasul) e o Foro Consultivo de Municípios, Estados Federados, Províncias e Departamentos do Mercosul (FCCR). Procura-se identificar os parâmetros que balizam as suas respectivas composições e, a partir daí, tenta-se pensar a questão da representação. O texto está dividido em quatro partes: 1) $\mathrm{O}$ conceito de representação e suas limitações; 2) O Mercosul como instituição representativa do Cone Sul: o problema da legitimidade e do déficit democrático; 3) O Parlamento do Mercosul (Parlasul); 4) O caso do Foro Consultivo de Municípios, Estados Federados, Províncias e Departamentos do Mercosul (FCCR); seguidas das conclusões.

\footnotetext{
2 A europolítica em sua configuração presente e provisória não é uma democracia e não se ornará uma a não ser que seus estados-membros decidam explicitamente a dotar de novos direitos e regras" (tradução dos revisores).
} 


\section{O CONCEITO DE REPRESENTAÇÃO E SUAS LIMITAÇÕES}

A representação é o principal elemento discriminante entre o conceito de democracia formulado pelos gregos antigos e o de seus epígonos: enquanto sua construção tal como elaborada no século de Péricles é caracterizada por uma assembléia de cidadãos aptos a decidirem diretamente sobre os assuntos referentes à polis ${ }^{3}$, a definição mais usual, atualmente, é pautada no sufrágio de mandatários políticos. Essa reformulação do conceito-chave da teoria democrática decorre, em síntese, da impossibilidade de sustentar um sistema político baseado na ação direta do cidadão que tem como locus fundamental o Estado ${ }^{4}$.

A adoção dessa democracia com base estatal representativa defronta-se, presentemente, com o surgimento das organizações regionais internacionais, instituições que abalam os alicerces da soberania estatal. A análise de como as garantias e problemas relativos à representação projetam-se nesses novos níveis de governança já é um instigante debate teórico no seio da União Européia (MORAVCSIK, 2002; HIX \& FOLLESDAL, 2005; MAJONE, 2005). Todavia, há que se analisar como tal problemática processa-se no seio do Mercado Comum do Sul (Mercosul), dada a criação de seus recentes fora regionais.

O marco teórico das discussões acerca de representação - historicamente relacionado à nacionalização da economia citadina (Heckscher apud HABERMAS, 2003, p. 31)-é associado a Thomas Hobbes e à sua análise sobre a forma e o poder do Estado. Anuência e delegação de autoridade são, na moldura criada pelo teórico, os elementos-chave de sustentação do poder constituído por meio do contrato original. Também significam, nesse campo de análise, a única alternativa de sobrevivência ao ser humano, o qual não resistiria ao estado natural: pelo fato dos homens naturalmente

\footnotetext{
3 A vida pública grega, neste caso, não é restrita a um só local. Ela abrange tanto os debates públicos, os conselhos e tribunais e a práxis comunitária, seja na guerra, seja nos jogos guerreiros. Segundo Habermas (2003, p. 15), legislar não faz parte da esfera pública, sendo a atividade muitas vezes delegada a estrangeiros.

4 O exercício pleno das prerrogativas democráticas pelo atual contingente de cidadãos ocasionaria crescente erosão da capacidade de governo, debilitando as próprias instituições democráticas (DINIZ, 1997, p. 47).
}

amarem a liberdade e a dominação sobre outros interesses contraditórios - a formação do Estado seria a única maneira de impedir a autodestruição da espécie. A constituição de um poder comum implica, por outro lado, a perda da liberdade do cidadão: "The only way to erect such a common power, as may be able to defend them from the invasion of foreigners, and the injuries of one another, and thereby to secure them in such sort as that by their own industry and by the fruits of the earth they may nourish themselves and live contentedly, is to confer all their power and strength upon one man, or upon one assembly of men, that may reduce all their wills, by plurality of voices, unto one will: which is as much as to say, to appoint one man, or assembly of men, to bear their person" (HOBBES, 1651, p. 107)

A constituição do Estado é, por conseguinte, pautada na delegação total de poder ao soberano. Hobbes considera representativo o governo formado após tal acordo porque o(s) detentor(es) da soberania encarna(m) os anseios do Povo, personificando as vontades da totalidade dos cidadãos (BOBBIO, 2000). Na abstração elaborada, a representação é uma necessidade. Isso porque apesar do homem ser originalmente dotado de poder político, ele não poderia utilizá-lo no estado natural, já que se trata necessariamente de uma situação de guerra contra todos. Segundo Held (1996, p. 78), Hobbes não objetiva convencer os indivíduos a contratar, mas, sim, persuadi-los sobre a naturalidade de suas obrigações para com o governante.

Percebe-se que a representação não se relaciona inicialmente à democracia, porém à legitimação de um governo autocrático. Tais conceitos somente começam a entrecruzar-se a partir do trabalho teórico de John Locke. Para ele, a representação é necessária porque o governo existe como fonte de proteção da defesa da propriedade, vida e liberdade do cidadão. Em última instân-

\footnotetext{
5 Tradução dos autores: "O único modo de exigir tal poder comum, com poder ser capaz de defendê-los da invasão de estrangeiros, e dos danos de um sobre o outro, e por meio disso assegurá-los de tal forma que por meio de sua própria dedicação e pelos frutos da terra eles possam se alimentar e viver com satisfação, é conceder todo seu poder e força a um homem, ou a uma assembléia de homens, que possa reduzir todas as suas vontades, por meio da pluralidade de vozes, em uma só vontade: o que é como dizer, nomear um homem, ou uma assembléia de homens, para sustentar sua pessoa".
} 
cia, é somente ele, através de seus representantes, quem pode decidir de que forma as políticas públicas garantirão tais valores. É evidente, neste caso, que a autoridade é depositada nos cidadãos, cabendo ao governo agir de acordo com a vontade do consenso entre indivíduos. Essa seria a única forma de garantir a sua legitimidade (idem, p. 81).

As preocupações de como pôr em prática os princípios estabelecidos na doutrina lockeana foram grandes incentivos para Montesquieu e Madison. O primeiro, ao se preocupar com inovações institucionais que garantisse o controle do governo representativo (por meio do balanceamento de poderes). O segundo, ao elaborar arranjos constitucionais que evitassem a tirania da maioria. Coube por sua vez a John Stuart Mill estabelecer uma relação mais direta entre democracia e representação, que para ele são fundamentais na garantia da liberdade do indivíduo. Como destaca Held (idem, p. 100): "Participation in political life - voting, involvement in local administration and jury service - was vital, he maintained, to create a direct interest in government and, consequently, a basis for an informed and developing citizenry, male or female, and for a dynamic "development polity" "6.

A base fornecida por tais pensadores é fundamental para a construção dos Estados atuais, os quais não atingem, na prática, os graus de democracia, legitimidade e representação política delineados na teoria. Uma premissa fundamental é, no entanto, assegurada: o povo é, nesse panorama, o verdadeiro detentor da soberania política, só a ele cabendo legitimar os governantes a agirem em seu nome e no nome de seus interesses, possuindo controle. Habermas (2003) denomina tal câmbio em relação ao Estado moderno de constitucionalização de uma esfera pública ${ }^{7}$, na

\footnotetext{
6 Tradução dos autores: "Participação na vida política votando, envolvimento em administração local e serviço de jurado - era vital, ele sustentava, para criar um interesse direto no governo e, conseqüentemente, a base para um conjunto de cidadãos informado e desenvolvido, homem ou mulher, e para uma dinâmica 'política de desenvolvimento",.

7 A esfera pública é compreendida como um contingente de pessoas reunidas em um público. $\mathrm{O}$ espaço de reivindicação da esfera pública nos Estados democráticos de Direito é assegurado constitucionalmente, por meio da criação de mecanismos de aferição da opinião pública (por exemplo, o voto periódico).
}

qual ela surge "atuando politicamente como órgão do Estado para assegurar institucionalmente o vínculo entre lei e opinião pública" (HABERMAS, 2003, p. 101).

Apesar dessa mudança de perspectiva e das alterações institucionais estarem relativamente consolidadas, os entraves locais relativos à representação política ainda permanecem. De acordo com Held, o modelo de democracia liberal não é capaz de processar as condições para a possibilidade de uma participação política, formas de controle democrático e o escopo democrático do decision-making (Held apud VILLA, 2006). Todos esses impasses são maximizados quando se expandem os limites geográficos - o que gera o questionamento sobre qual é o locus territorial ideal para o conceito de democracia como prática internacional.

As ORIs surgem como uma arena sociopolítica e econômica suplementar aos já existentes níveis nacional e subnacional. Com esses níveis ela imbrica-se em movimento de realocação de competências, ressuscitando, de tal modo, questões ligadas à democracia, representação e legitimidade. Essa nova realidade, contudo, vem, no mais das vezes, sendo apreendida tão-somente sob a ótica dos conceitos elaborados para serem conferidos ao sistema político estatal. Elementos de anacronismo metodológico podem, assim, ser identificados, dificultando a compreensão de mecanismos genuínos, derivados de novas formas de relacionamento. Como nota Moravcsik (2002, p. 605): "Comparisons are drawn between the EU and an ancient, Westminster-style, or frankly utopian form of deliberative democracy. While perhaps useful for philosophical purposes, the use of idealistic standards on modern government can meet obscures the social context of contemporary European policy-making - the real-world practices of existing governments and the multi-level political system in which they act"8.

\footnotetext{
8 Tradução dos autores: "Comparações são traçadas entre a UE e uma antiga, estilo Westminster, ou francamente utópica forma de democracia deliberativa. Enquanto talvez útil para propósitos filosóficos, o uso de padrões idealistas com que governos modernos podem se deparar obscurece o contexto social das decisões políticas européias atuais - a prática real dos governos existentes e o sistema político multinível no qual eles agem".
} 
Exemplificando, se tomarmos por base a clássica definição de Schumpeter (1975, p. 269) para democracia - arranjo institucional em que os indivíduos adquirem o poder de decisão política mediante uma competição pelo voto popular - e a sua afirmação de que "o método eleitoral é praticamente o único disponível para comunidades de qualquer tamanho" (idem, p. 271), o regime estabelecido nas Organizações Regionais Internacionais é de pronto considerado deficitário, dado que os órgãos compostos por representantes populares, se existentes, não são protagonistas no processo decisório. Todavia, o modelo a ser aplicado na análise da governança regional é passível de reformulação, visto que sua circunscrição é maior e mais complexa que a do Estado. Em sua essência, as alterações na estrutura do sufrágio e no controle democrático surgem pela necessidade de realizar trade-offs entre "exercício e controle direto da democracia pelo indivíduo" e "capacidade de resolução de problemas por sistemas territorial e demograficamente maiores". É o acentuado por Dahl (1994, p. 28): "Taken to an extreme but perhaps not wholly fanciful limit, the paradox would pose a choice between a tiny unit in which citizens could exercise perfect democratic control over, say, the location and upkeep of footpaths; or a world government necessary for preserving life on the planet by preventing acute environmental degradation, but over which citizens had only symbolic democratic control" 9 .

A experiência da União Européia, como Organização Regional Internacional, surge, nesse sentido, inovadora. Nela, alguns traços de invenção política no que concerne as questões de representação, legitimidade e democracia podem ser identificados. Um dos principais deles constituindo-se no princípio de "subsidiariedade", que, apesar de ser historicamente encontrado no seio da lógica dos processos de federalização de Estadosnação, assume contornos genuínos na dinâmica integracionista da Europa. Como sublinha Delors: "Qui dit acceptation du principe de subsidiarité dit

\footnotetext{
9 Tradução dos autores: "Levado a um extremo, mas talvez não totalmente imaginário limite, o paradoxo proporia uma escolha entre uma pequena unidade na qual os cidadãos pudessem exercer um controle democrático pleno sobre, digamos, a localidade e a manutenção de possibilidades; ou uma governança mundial necessária para preservar a vida no planeta por meio da prevenção de uma acentuada degradação ambiental, mas na qual os cidadãos tivessem somente um controle democrático simbólico".
}

respect du pluralisme et donc des diversités. [Il permet en effet de] concilier ce qui apparaît à beaucoup comme inconciliable : l'émergence de l'Europe unie et la fidélité à notre nation, à notre patrie ; la nécessité d'un pouvoir européen, à la dimension des problèmes de notre temps, et l'impératif vital de conserver nos nations et nos régions comme lieu d'enracinement" (Delors apud JEHAN, 2007, p. 21) ${ }^{10}$.

A criação e a evolução do Parlamento Europeu (PE) e, principalmente, do Comitê de Regiões (CdR) da UE refletem, em parte, a tentativa de se responder aos anseios de controle dos cidadãos por meio da adaptação dos mecanismos de accountability concebidos precipuamente dentro do quadro do Estado-nação. Trata-se, sem embargo, de um mimetismo institucional endógeno, inspirado em grande parte nas práticas políticas próprias aos Estados-membros, mas contendo germe inventivo que denota a necessidade de se levar em conta as demandas mais prementes da pós-modernidade: máxima celeridade na tomada de decisões e participação cidadã - associada, não raro, a um dispositivo de representação eficiente.

Esse germe inventivo, claro está, não é novo. Ernst Haas, inspirando-se na obra de Karl Deutsch (1957), retoma a idéia de lealdade por ele explorada para definir "comunidade política", conceito ímpar forjado com o fito de entender os anseios teleológicos encerrados pelos Tratados de Paris e de Roma: "Political community [...] is a condition in which specific groups and individuals show more loyalty to their central political institutions than to any other political authority, in a specific period of time and in a definable geographic space" (HAAS, 2004, p. 5) ${ }^{11}$.

Na consecução da "comunidade política", três atores preponderam: os grupos de interesse, os

\footnotetext{
10 Tradução dos autores: "Quem diz aceitação do princípio de subsidiaridade, diz respeito ao pluralismo e assim às diversidades. [Ele permite, com efeito,] Conciliar o que parece inconciliável: o surgimento de uma Europa unida com a fidelidade à nossa nação, à nossa pátria; a necessidade de um poder europeu consoante à dimensão dos problemas de nosso tempo, com o imperativo vital de conservar nossas nações e nossas regiões como lugar de enraizamento".

11 "A comunidade política [...] é uma condição em que grupos e indivíduos específicos demonstram maior lealdade para as suas instituições políticas centrais que para qualquer outra autoridade política, em um período específico e em um espaço geográfico definido" (N.R.).
} 
partidos políticos e os governos nacionais. Todos devem atestar um comprometimento inequívoco com a ação supranacional. Todavia, contrariamente a Deutsch (1954), o esquema proposto por Haas considera as instituições políticas - enquanto instrumento capaz de transformar ideologia em norma - como pedra angular dessa definição (idem, p. 7). Também, para ele, a idéia de "comunidade política" não pressupõe, necessariamente, o surgimento de um Estado federal, embora isso possa, sem dúvida, ocorrer.

A situação no Mercado Comum do Sul é diferente. Seu grau de institucionalização é bem mais modesto que o da UE. O enquadramento da cooperação intergovernamental (MEDEIROS, 2000) situa-se aquém da realidade supranacional de determinados setores da União Européia, tais como a política comercial ou monetária, entre outros. Contudo, o Mercosul não pode, inversamente, ser compreendido como uma mera zona de livre comércio. Ele ambiciona, desde seus primórdios, ser um projeto político-social e, como tal, busca instrumentos capazes de assegurar a gestão pública democrática de um espaço regional comum. E, de fato, os laços hoje existentes entre os Estados que o compõem superam as fronteiras estritamente mercantis, mesmo se o comércio persiste como elemento fundamental da lógica integracionista. A criação do Parlasul e, mais recentemente, a instauração do Foro Consultivo de Municípios, Estados Federados, Províncias e Departamentos do Mercosul (FCCR) demonstra, apesar das suas peculiares limitações internas, vontade política dos tomadores de decisão em organizar processos efetivos por meio da sua institucionalização. E isso, no rastro do ocorrido com a UE, ou seja, o sistema político embrionário do Mercosul padece do mal generalizado no seio das ORIs, a saber, encontrar um modus operandi singular descolado dos cânones políticos centenários do Estado-nação, sem entretanto dilapidar alguns dos princípios caros à natureza humana: liberdade, participação, legitimidade, controle e representação.

Assim, depois de encetar estes prolegômenos relativos ao tema da representação e também de delinear o contorno da questão no cenário atual, focase a discussão nas instituições de caráter representativo do Mercosul, a saber, o Parlasul e o FCCR.

\section{O MERCOSUL COMO INSTITUIÇÃO RE- PRESENTATIVA DO CONE SUL: O PRO- BLEMA DA LEGITIMIDADE E DO DÉFI- CIT DEMOCRÁTICO}

Desde seus primórdios, os estados-partes do Mercosul têm demonstrado interesse em expandir as relações intrabloco para além da arena comercial. Tal disposição em atribuir à instituição maior poder representativo pode ser precisamente observada na implantação do FCCR e do Parlasul. Os dois novos órgãos têm por objetivo principal - respectivamente - representar as unidades subnacionais e a população dos Estadospartes dessa Organização Regional Internacional.

A criação de novos espaços de representação pública distintos dos fundados sob a égide do Estado-nação foi o mecanismo utilizado, pioneiramente, pela União Européia (UE) objetivando aprofundar a integração regional por meio da inserção de mandatários políticos em seu processo legislativo. O projeto do Mercosul mostra-se, até então, mais modesto, sendo tanto o Parlasul quanto o FCCR instituições consultivas, o que limita consideravelmente sua influência no processo decisório.

A necessidade de representação no plano regional pode ser caracterizada como uma espécie de controle em relação às decisões politicamente vinculantes tomadas por esses mandatários, a fim de que seja levado em consideração o interesse dos indivíduos influenciados por essas decisões. Acaba-se, assim, por se estabelecer uma tensão entre o poder necessário a ser delegado para a promoção de interesses coletivos e o controle imprescindível à proteção do cidadão da má gestão pública. De acordo com O’Donnell (2004), o desejo simultâneo por efetividade decisória e por controle é tão racional quanto contraditório.

A fim de atingir o equilíbrio entre ambas as vontades, é necessário garantir a legitimidade do sistema político - aqui compreendida como a capacidade de manter a crença de que as instituições estabelecidas são as mais eficazes para promover o bem estar da sociedade (LIPSET, 1967). Considera-se que a legitimação das ORIs desenvolve-se em dois níveis: 1) a identificação entre esfera pública e organização supranacional e 2) a diminuição do déficit democrático por meio da instituição de mecanismos de controle. 
O primeiro nível, que consiste no processo de formação de identidade transnacional, envolve um complexo de práticas e atitudes favoráveis ao estímulo dos cidadãos na construção de sua identidade política regional. Ele forja o que Elias (1997, p. 9) denomina de habitus, ou seja: segunda natureza ou saber social incorporado. Nesse caso, um habitus supranacional - um demos proteiforme e incipiente que, paulatinamente, vai sendo reificado. A identificação com a organização regional internacional resultaria numa postura diligente por parte do indivíduo, no sentido de cobrar direitos e assumir obrigações, além de tentar obter benefícios por meio da instituição.

O deslocamento do conceito de legitimidade para níveis transnacionais evidencia um problema já parcialmente controlado no plano estatal. Considerando que sua construção aponta para a importância de processos prolongados de socialização política dos indivíduos, a fim de internalizar valores de apoio ou rejeição à instituição ou às suas partes constituintes, pode-se alegar que tal identidade cidadão-sistema político é, ao longo de séculos, construída em nível estatal, mas que ainda não pode ser verificada na maior parte das ORIs, em geral e, no Mercado Comum do Sul, em particular. Daí a importância de eventos como o Dia do Mercosul12, a uniformização de passaportes expedidos pelos estados-partes, contendo a menção Mercosul-Mercosur em sua capa, e a criação do "Somos Mercosul"13, para, por meio da simbologia e do imaginário, estimular o sentimento de pertencimento, o estado de civitas em indivíduos que se sentem comprometidos tão-somente com manifestações democráticas no limite de seu Estado. Esforça-se para instigar o surgimento de novas lealdades, agora situadas no nível transnacional.

\footnotetext{
12 Por proposta do Parlamento, o Conselho do Mercado Comum estabeleceu o "Dia do Mercosul Cidadão", para a eleição dos parlamentares, de forma simultânea em todos os Estados Partes, por meio de sufrágio direto, universal e secreto dos cidadãos. A instituição de tal dia é de valor simbólico relevante, visto que contribui para estreitar as identidades regionais para a formação de uma esfera pública transnacional.

13 “Somos Mercosul” é uma iniciativa pública, lançada pela Presidência Pro Tempore do Uruguai em 2005, que tem por objetivo envolver a cidadania no processo da integração regional, gerando novos espaços onde a sociedade civil e os governos locais possam debater, formular demandas e participar dos processos decisórios.
}

A internalização de uma esfera social regional é necessária porque enquanto a idéia de sentimento nacional acaba por ser bastante reproduzida entre os indivíduos de um país, uma identificação transnacional é, no mínimo, questionável, já que a democratização de instituições supranacionais ainda é muito embrionária. Ou, na acepção de Elias (ibidem), o saber social incorporado representado pelo habitus marcaria a dinâmica circunscrita pelas fronteiras estatais, mas não aquelas situadas além delas - mesmo se delimitadas por outras de ordem regional.

Essa identificação entre cidadão e ORI propicia o surgimento da accountability societária vertical, sendo ela um tipo de "mecanismo não-eleitoral, mas vertical, de controle de atividades públicas que reside nas ações de um múltiplo conjunto de associação de cidadãos e de movimentos [...] ação que tem como objetivo a exposição dos erros governamentais, trazendo novas questões à agenda pública" (Smulovitz \& Peruzzotti apud O'DONNELL, 2004 , p. 24) ${ }^{14}$. Tal tipo de accountability é de extrema importância em países latino-americanos, nos quais o controle por meio da votação é muitas vezes deficiente (idem, p. 25).

Como as políticas afirmativas de uma identidade "mercosulina" ainda são relativamente recentes, a UE acaba por ser um recorrente parâmetro de comparação em relação à eficácia do processo de integração. O Eurobarometer, série de pesquisas de opinião pública realizadas pela Comissão Européia, a fim de aferir o grau de identificação entre os cidadãos e a Europa, fez a seguinte pergunta: "Você se sente ligado à Europa?". O resultado foi que seis entre dez entrevistados sentemse muito ou bastante ligados à Europa, sendo os habitantes de Luxemburgo os que apresentam as mais altas taxas de identificação (78\%). Além desse sentimento de familiaridade geográfica, buscouse também determinar o grau de ligação psicológica entre cidadão e UE. O instituto perguntou: "Existe uma identidade européia?". A tabela a seguir expressa os resultados obtidos, demonstrando eficácia considerável de políticas de legitimação de identidade regional.

\footnotetext{
14 No original: "mecanismo no electoral, pero vertical, de control de autoridades políticas que descansa em las acciones de um múltiple conjunto de asociaciones de ciudadanos y de movimientos [...] acción que tiene como objectivo el exponer de los errores gubernamentales, trayendo nuevas cuestiones a la agenda pública”.
} 
TABELA 1 - PESQUISA: EXISTE UMA IDENTIDADE EUROPÉIA?

\begin{tabular}{|l|c|c|c|c|}
\hline PAís & $\begin{array}{c}\text { SOMENTE } \\
\text { EUROPÉIA (\%) }\end{array}$ & $\begin{array}{c}\text { EUROPÉIA E } \\
\text { NACIONAL(\%) }\end{array}$ & $\begin{array}{c}\text { NACIONALE } \\
\text { EUROPÉIA (\%) }\end{array}$ & $\begin{array}{c}\text { SOMENTE } \\
\text { NACIONAL (\%) }\end{array}$ \\
\hline Luxemburgo & 20 & 11 & 41 & 23 \\
Bélgica & 7 & 8 & 42 & 41 \\
Itália & 6 & 9 & 56 & 26 \\
Países Baixos & 1 & 5 & 49 & 44 \\
França & 4 & 7 & 48 & 39 \\
Espanha & 4 & 6 & 53 & 31 \\
Alemanha & 4 & 8 & 37 & 48 \\
Áustria & 3 & 5 & 42 & 47 \\
Irlanda & 3 & 4 & 38 & 53 \\
Reino Unido & 3 & 3 & 24 & 67 \\
Dinamarca & 3 & 3 & 37 & 56 \\
Portugal & 2 & 2 & 42 & 52 \\
Suécia & 2 & 4 & 32 & 61 \\
Finlândia & 1 & 3 & 35 & 61 \\
Grécia & 1 & 2 & 38 & 60 \\
EU - 15 & 4 & 6 & 42 & 45 \\
\hline
\end{tabular}

FONTE: Comissão Européia (1999).

NOTA: O sombreamento indica os países em que o grau de identidade européia supera a identidade somente nacional.

No que diz respeito ao segundo nível de legitimação a ser discutido, a que podemos associar a questão do déficit democrático, o cerne do problema é a eficácia da representação proposta, tangenciando mecanismos de freios e contrapesos, accountability, e intervalo entre demanda populacional e ação institucional.

Como já enfatizado, a legitimação de um governo democrático desde muito tempo não é assegurada por meio da participação direta dos cidadãos - apesar de ser ela esporadicamente possível - e, sim, pela capacidade de controle em relação aos procedimentos adotados e pela possibilidade aberta aos cidadãos de expor periodicamente sua recusa ou aceitação das decisões e dos resultados apresentados pelo governo (BRUNKHORST, 2006).

Segundo Villa (2006), já está previsto no âmago da democracia representativa o seu custo de governabilidade, ou seja, a previsibilidade de um descompasso entre, por um lado, a capacidade da sociedade civil e de suas instituições em demandar ação pública e, por outro lado, a resposta a tais estímulos. Tal lapso temporal entre demanda e resposta faz parte dos procedimentos que visem à satisfação do consenso. $\mathrm{O}$ autor ainda explicita que "em um contexto democrático contemporâneo, valores como o procedimento e as formas institucionais que dão aos cidadãos comuns acesso ao poder político instituído são fundamentais para a realização de um Estado Democrático" (idem, p. 85).

O problema, tomando por base o locus estatal, evidencia-se na prática quando não se proporciona ao indivíduo a oportunidade de eleger representantes para tomadas de decisão. Tal situação é igualmente observada quando a representação se dá num nível sub-ótimo, isto é, quando o instrumento de votação acaba por não atender seus objetivos fundamentais, de modo geral, quando uma câmara representativa não exerce papel significativo nos processos de governança em detrimento de um poder não eleito ${ }^{15}$. A projeção dessas demandas nas ORIs e a dedução de que, por não responderem satisfatoriamente a elas, tais organismos transnacionais são de pronto democrati-

\footnotetext{
15 É o caso tanto do Parlasul quanto do FCCR, que têm sua influência limitada pelo seu caráter exclusivamente consultivo. O Parlamento Europeu tem, no quadro do procedimento dito de codecisão, poder de veto no processo legislativo da UE.
} 
camente deficitários e carecem de legitimidade é questionada por parte dos especialistas em integração regional.

Ao abordar o tema, Andrew Moravcsik (2002) considera o sistema político europeu legítimo, e o problema do déficit democrático, ilusório. Segundo ele, o fato da UE apresentar-se relativamente distante do cidadão não a desqualifica como instituição democrática. Ao contrário: se forem adotados critérios racionais para caracterizar o que seria democrático dentro do contexto atual, a UE estaria contida em tal conjunto. Em verdade, os parâmetros a serem considerados são controles estabelecidos constitucionalmente, fiscalização indireta por meio dos governos nacionais e o aumento de poder gradualmente concedido ao Parlamento Europeu. Além disso, deve-se considerar que o objetivo da UE - e isso se aplica ao Mercosul - não é se tornar um super-Estado: "Yet the threat of a European superstate is a myth"16 (MORAVSIK, 2002, p. 606). Isso porque impera a necessidade de um consenso na tomada de decisões aliada a uma reduzida autonomia fiscal. Em suma, enquanto os Estados permanecerem como foro principal de demandas - e como mecanismo de accountability indireta - não há que se falar em déficit democrático no plano transnacional.

Em sua resposta a Moravicsik, Majone (2006) concorda que deliberação e participação não se relacionam diretamente com legitimidade política. Ele difere, no entanto, quanto às formas de garantir a legitimidade da instituição. Para ele, a competência concedida à UE pelos estados-membros é de agência regulatória em áreas específicas e, por isso, não há necessidade de compatibilizar a ORI com os sistemas majoritários de controle, já que isso levaria inexoravelmente a uma politização das decisões a serem realizadas em cada setor regulado. O problema não seria, portanto, o déficit democrático, mas uma crise de legitimidade da instituição pela falta de credibilidade das agências reguladoras que a formam. Tal credibilidade é que deveria ser acentuada.

Contrapondo-se à conclusão de ambos os autores, Hix e Follesdal (2006) alegam a existência do déficit democrático, partindo de uma premissa fundamental na teoria democrática: os processos de decisão que ocorrem no seio da UE carecem

\footnotetext{
16 "Ainda assim, a ameaça de um super-Estado europeu é um mito" (N.R.).
}

de discussões acerca de opções políticas, impossibilitando a formação de uma postura por parte do cidadão. Assim, por serem elaboradas por tecnocratas, sem que haja o devido debate entre partidos políticos, as decisões adotadas acabam, muitas vezes, sendo interpretadas como ilegítimas, já que em condições normais seriam rechaçadas pela população. Em suma, a ausência de uma oposição genuína e a blindagem do manto tecnocrático restringem o exercício da escolha, elemento caro a toda dinâmica cidadã.

No caso do Mercosul, essas questões mostram-se ainda mais patentes, visto que a hipertrofia dos poderes Executivos nacionais e da tecnocracia é acentuado pela débil competência das instâncias representativas, entre elas o FCCR e o Parlasul. O tema das seções seguintes é a legitimidade de ambas as instituições, considerando tanto os modelos de representação e do déficit democrático construídos sob uma lógica estatal quanto os elaborados para processos regionais de integração.

\section{O PARLAMENTO DO MERCOSUL (PAR- LASUL)}

Esse seção tem como objetivo o estudo do Parlamento do Mercosul, suas características institucionais e a importância que esse tem para a integração regional na região do Cone Sul. Para isso, primeiramente, analisa-se o processo de formação do órgão, fazendo-se uma breve comparação com os problemas tratados no âmbito da União Européia e, mais especificamente, do Parlamento Europeu, atentando, sobretudo, para as questões relativas ao déficit democrático e a accountability. Essa rápida comparação justifica-se devido ao peso que a ORI européia e suas instituições têm, no aspecto de um "grande laboratório", para os outros processos integracionistas (MEDEIROS, 2003). Em seguida, a seção detém-se aos diferentes níveis de importância que a nova instituição apresenta para os atores regionais do âmbito "mercosulino" e para os possíveis interesses que esses últimos possam apresentar.

Rittberger (2003) aponta o problema do déficit democrático como inerente aos processos de integração regional. Defendendo essa linha, Tostes (2004) chama a atenção para duas variáveis que compõem esse fenômeno no âmbito da União Européia. Primeiramente, existe a falta de accountability de algumas instituições que não tem seus membros eleitos pelos cidadãos; em segundo lugar, a ausência de conscientização e partici- 
pação dos próprios cidadãos com relação ao processo de integração. A autora coloca, por exemplo, que o escrutínio para o Parlamento Europeu apresenta um caráter secundário para os eleitores, cuja participação vem caindo gradativamente a cada nova eleição. No entanto, contrariando essa perspectiva, Moravcsik (2002) defende que o sistema político da União Européia, devido a seus esforços institucional-democráticos, comparado com os sistemas políticos vigentes nas democracias avançadas, apresenta pouca evidência de déficit democrático.

Entre as instituições comunitárias da OIR européia, o PE é a que os cidadãos dão mais importância (TOSTES, 2004). Mesmo não sendo a principal instância decisória do bloco regional, ela vem se fortalecendo e ganhando poderes políticos desde a sua criação - especialmente depois da introdução do mecanismo de codecisão ${ }^{17}$, pelo Tratato de Maastricht. A instância decisória máxima da União Européia continua sendo o Conselho Europeu, composto pelos chefes de Estado e de Governo dos países membros.

No âmbito mercosulino, o Parlasul foi criado em 2006, por decisão do Conselho do Mercado Comum (CMC). O novo órgão vem para substituir a Comissão Parlamentar Conjunta (CPC), que, apesar de sua importância, teve uma atuação limitada ao longo do processo de integração (CONSELHO DO MERCADO COMUM, 2005).

A comissão (CPC) foi criada pelo Tratado de Assunção (1991), sendo então formada por 64 parlamentares, dezesseis de cada Estado-membro, designados pelos respectivos Congressos Nacionais. Os parlamentares agrupam-se por delegações nacionais e as decisões tomadas pelo órgão devem levar ao consenso o conjunto das delegações. O seu papel é eminentemente consultivo.

Pode-se colocar que a atuação da CPC no processo integracionista do Mercosul, ao longo da década de 1990, é bastante restrita (VIGEVANI, OLIVEIRA \& MARIANO, 2000, p. 261-275). Em

\footnotetext{
17 O mecanismo de codecisão, quando aplicado, atribui ao Parlamento Europeu o poder de veto no processo legislativo da União Européia. A partir da entrada em vigor do Tratado de Amsterdã (1997), o procedimento de codecisão (art. 251) aplica-se a 39 bases jurídicas do Tratado da Comunidade Européia (1992), que permitem a adoção de atos legislativos.
}

grande parte devido à sua debilidade institucional, conseqüência de seu fraco poder político dentro do bloco (ANTÓN \& CAETANO, 2001; GENEYRO \& VÁZQUEZ, 2006). Somente nos seus últimos anos é que o órgão apresentou resultados mais concretos, como o acordo CMC-CPC, em $2003^{18}$, e a criação do Parlasul, em 2006.

Ainda em fase de implantação, o Parlasul deve ser instalado em duas etapas. Na primeira, entre 31 de dezembro de 2006 e 31 de dezembro de 2010, o órgão deve ter 18 parlamentares de cada Estado-membro, indicados pelas respectivas instâncias legislativas nacionais. Antes de finalizada essa primeira etapa, devem ser realizadas eleições diretas, que devem acontecer em datas escolhidas segundo cada membro. Assim, já no começo da segunda etapa - que vai de $1^{\circ}$ de janeiro de 2011 a 31 de dezembro de 2014 - todos os parlamentares devem ter sido eleitos de forma direta. A primeira eleição conjunta realizar-se-á antes do final de 2014.

Com a eleição direta, os parlamentares têm seus mandatos somente atrelados ao Parlasul. Isso constitui uma importante mudança, pois como lembram Feld e Wildgen (1975) para o caso do PE, como os parlamentares têm seus mandatos atrelados aos Congressos Nacionais até 1979, eles tendem a dar menor importância a suas atividades no órgão regional. Murray (2004, p. 104) também partilha dessa visão com relação ao órgão europeu nesta fase, colocando que, em caso de ambivalência, os parlamentares tendem a dar preferência ao nível nacional. Afinal, a reeleição acontece nesse nível, sendo necessário antes de ser membro do parlamento regional, ser membro do parlamento nacional. Além disso, neste período, as atividades no $\mathrm{PE}$ podiam, muitas vezes, não oferecer nenhum ganho material ou eleitoral (no nível nacional) para os seus membros. Pelo contrário, Feld e Widgen (1975) mostram que alguns

\footnotetext{
18 Em outubro de 2003, na sua quarta reunião extraordinária, o CMC celebrou um acordo com a CPC para tornar mais eficiente a incorporação das normas mercosulinas nos arcabouços jurídicos dos estados-partes. Por esse acordo, o Conselho comprometeu-se a consultar a Comissão acerca dos assuntos que necessitem de incorporação legislativa nos países-membros. Do seu lado, a Comissão comprometeu-se a agilizar, por meio das bancadas nacionais, a interiorização das normativas mercosulinas, especialmente as que sejam produto de consenso CPC-CMC.
} 
parlamentares tinham a idéia de que os custos das atividades no parlamento regional podiam chegar a prejudicar o mandato nacional.

Outro ponto a ser tocado com a eleição direta, seria um possível fortalecimento de uma cultura regionalista e um maior otimismo para com o processo integracionista. Pois não se pode olvidar que o Parlamento Europeu ganha importância crucial a partir das primeiras eleições diretas (1979), já que, a partir dessas, uma onda de otimismo para com o processo integracionista surge (ALMEIDA, 1998). Seguindo nessa direção, Hix (2003, p. 192) assinala que, a partir da primeira eleição comunitária européia, acontece um crescimento sem precedentes no volume de publicações científicas sobre o órgão. É possível que aconteça fenômeno semelhante com o caso "mercosulino". Isso viria a refletir, então, a crescente importância social e política que o Parlasul apresentaria.

Além das eleições diretas, o novo parlamento regional trouxe outras três relevantes mudanças em relação à CPC. Primeiramente, o fim da necessidade de consenso para tomada de decisões. No Parlasul, o critério de decisão passa a ser o estabelecimento de maiorias que variam segundo a matéria a ser votada. Isso aumenta claramente a dinamicidade do órgão. Pois mesmo com as decisões por unanimidade apresentando alto grau de legitimidade, Sharpf (2006) aponta para o problema de que, nestes sistemas, o veto de um pode impedir as preferências de todos os outros. Completando essa afirmação, Tsebelis coloca que sistemas de negociação com múltiplos veto players perdem progressivamente sua capacidade de inovação política (Tsebelis apud SHARPF, 2006).

A segunda mudança se dá pela adoção de uma fórmula que efetua uma distribuição proporcional do número de cadeiras em relação à população. Até o presente momento, todos os membros contam com o mesmo número de representantes. No caso mercosulino, essa é uma questão complicada, pois um de seus membros, o Brasil, detêm mais da metade da população do bloco. Dessa forma, para se chegar a um consenso na distribuição de assentos, possivelmente este país deverá aceitar uma situação de sub-representação frente a países bem menores, especialmente, Uruguai e Paraguai. Tal qual ocorre no PE, em que a relação representante-representado é favorável aos ditos pequenos países (Luxemburgo, Malta ou Chipre) em detrimento dos ditos grandes (Alemanha, França, Itália ou Reino Unido).

A partir disso, deve-se mencionar, então, uma característica intrínseca aos parlamentos regionais. Neles, mesmo o menor Estado-membro tem direito de ser representado apenas pelo fato de existir; ao contrário do que ocorre com um partido em relação a um parlamento nacional, que não tem esse direito adquirido (HOSLI \& TAAGERA, 2006, p. 374). Assim, a sobre-representação dos membros menores do Parlamento Europeu, em relação ao tamanho das suas populações, pode ser claramente notada e compreendida (HOSLI, 1997).

A terceira mudança acontece com a possibilidade de formação de grupos políticos. Segundo o Regimento Interno (PARLAMENTO DO MERCOSUL, 2007), um grupo político deve ser integrado por pelo menos $10 \%$ de todo os parlamentares, se todos são da mesma nacionalidade; ou apresentar no mínimo cinco parlamentares, caso mais de um Estado-membro esteja representado. Isso poderá fortalecer o órgão mercosulino, já que, analisando o caso europeu, Murray (2004) afirma que os grupos partidários do PE, entre 1952 e 1979, foram importantes instrumentos para se propor o aumento do poder do órgão, sendo elementos de pressão frente ao Conselho Europeu. Assim, Hix, Noury e Roland (2006) delineiam o $\mathrm{PE}$ atual como uma instituição que representa interesses transnacionais, fazendo contraposição aos interesses nacionais presentes no Conselho. Sem embargo, a criação de grupos políticos permite a transversalidade de lealdades, isto é, se outrora elas estavam essencialmente restritas a uma base nacional, doravante elas podem se ancorar em comunhões ideológicas supranacionais e, por conseguinte, contribuir para a consolidação de um espaço público comum de representação.

Pode-se notar que o Parlasul está mais próximo do que a CPC do modelo típico de parlamento das democracias ocidentais, ou mesmo, do próprio Parlamento Europeu. Na linha do Parlasul, o PE toma decisões por votação, tem uma distribuição do número de assentos que leva em conta a população de cada Estado-membro, apresenta grupos políticos e tem eleições diretas. 
TABELA2 - COMPARAÇÃO DO DESENHO INSTITUCIONAL DO PARLAMENTO EUROPEU, DO PARLASUL EDA CPC

\begin{tabular}{|l|c|c|c|}
\hline & PE & PARLASUL & CPC \\
\hline Tomada de decisões & Votação & Votação & Consenso \\
Distribuição do número de assentos & Proporcional & Proporcional & Igualitária \\
Divisão das bancadas & Grupos políticos & Grupos políticos & Grupos nacionais \\
Eleições diretas & Sim & Sim & Não \\
\hline
\end{tabular}

FONTE: Conselho do Mercado Comum (2005); Malamud e Souza (2005); Parlamento do Mercosul (2007).

Contudo, o Parlamento Europeu desempenha funções legislativas, de controle e codecisão no ambiente político-institucional da União Européia, poderes institucionais de grande importância que o Parlamento do Mercosul não apresenta. Ao contrário da maquete européia, todos os órgãos decisórios e de controle mercosulinos são compostos por representantes dos poderes Executivos nacionais. Assim, coloca-se uma grande dificuldade na participação de setores não associados a burocracias governamentais no processo decisório de integração (WANDERLEY, 2002). Destarte, o Parlasul, um órgão representante da sociedade civil, possui, em rigor, semelhantemente à $\mathrm{CPC}$, apenas um caráter consultivo.

Portanto, considerando o déficit democrático um fenômeno inerente aos processos políticos, em geral, e aos de integração regional, em particular, a aquisição de poderes institucionais pelo Parlasul pode significar uma forma de atenuar este problema. Contudo, isso depende da visão que o Conselho do Mercado Comum tem desse fenômeno. Ao analisar o processo de fortalecimento do PE, Rittberger (2003) coloca que a visão sobre o déficit de legitimidade difere de acordo com o país e com sua elite política; logo, não é certo que todos os governos percebam a diminuição desse problema por meio do desenvolvimento de um órgão regional de caráter representativo. Por isso, como apontam Malamud e Sousa (2005), não se pode negligenciar o forte caráter presidencialista da região como um fator que faz os chefes de governo do Mercosul agirem com prudência no que concerne ao fortalecimento de órgãos regionais de representação.

Uma questão importante a ser colocada nesse ponto é a do incentivo que um candidato teria para se candidatar a um órgão consultivo, o qual não tem poderes direitos sobre o processo de integração. Nesse sentido, abre-se o risco da possibilidade de que o Parlasul venha a se tornar um órgão com pouca eficiência e altas despesas, em que parlamentares em fim de mandato, ou mesmo que tem dificuldade de se reeleger em seus respectivos países, queiram a ocupar as suas cadeiras.

Contudo, mesmo se o Parlasul não apresenta, até o momento, poderes institucionais decisórios de grande relevância para o processo de integração, o órgão se mostra com diferentes graus de importância para determinados grupos. Isto pode ser observado por meio da sobre-representação de determinadas regiões políticas nas bancadas dos dois maiores membros do bloco, Brasil e Argentina.

Uma variável importante para explicar esse fenômeno pode advir do processo de internalização pelo qual devem passar as normas "mercosulinas". Elas têm, em função da sua natureza, que ser aprovadas pelos parlamentos nacionais antes de entrar em vigor no espaço comunitário. Portanto, mesmo o Parlamento do Mercosul não sendo responsável direto pela internalização dessas normas, seus membros têm um papel importante nesse processo, podendo agir sobre ele a partir dos seus respectivos Legislativos - pelo menos enquanto seus membros estiverem dotados do duplo pertencimento, nacional e regional (o que não será mais o caso a partir de 2011). A partir daí se, por um lado, o Parlasul adquire maior autonomia, centralidade e representatividade - posto que seus membros serão eleitos diretamente - ele, por outro, perderá, ipso facto, sua capacidade de atuar de modo direto no seio dos parlamentos nacionais. $\mathrm{O}$ que sugere uma reflexão sobre os termos que pautarão as futuras relações entre Parlasul e parlamentos nacionais, principalmente enquanto o primeiro não dispuser de efetivos poderes legislativos.

Todavia, a sobre-representação tem espaço para acontecer devido ao fato das representações na- 
cionais tentarem refletir as bancadas partidárias dos respectivos Congressos Nacionais, e não a divisão regional ou populacional do país. Dessa forma, vários parlamentares de uma mesma região (que podem ter interesses no processo de internalização das normas "mercosulinas"), mas de partidos diferentes, podem fazer parte da delegação nacional no Parlasul.

A região argentina conhecida como Mesopotâmia, que faz fronteira com todos os estados-membros do Mercosul e engloba as províncias de Corrientes, Entre Rios e Missiones, mesmo apresentado somente um pouco mais de $8 \%$ da população e 4,5\% do Produto Interno Bruto nacional (INSTITUTO NACIONAL DE ESTADÍSTICA Y CENSOS, 2007), detinha, até setembro de julho de 2007, seis dos 18 assentos argentinos no Parlasul. Encontrando-se, desta forma, com um alto nível de representação se comparada com a região do Pampa, que incluí o distrito federal de Buenos Aires e as províncias de Buenos Aires, Córdoba, La Pampa e Santa Fé, que embora seja responsável por mais de $60 \%$ da população e quase três quartos do PIB (idem), detinha apenas cinco das 18 cadeiras.

No caso brasileiro, verifica-se, desde os tempos da CPC, a forte presença de parlamentares da Região Sul na bancada nacional. Em 1996, por exemplo, dos 16 parlamentares brasileiros que faziam parte da representação, 13 eram provenientes dessa região. Embora nela se encontre aproximadamente $15 \%$ da população brasileira (INSTITUTO BRASILEIRO DE GEOGRAFIA E ESTATÍSTICA, 2004), detinha quase $81,25 \%$ da representação do país na CPC. Em outubro de 2007, a região continuou a apresentar uma forte presença na bancada brasileira no Parlasul, embora em menor grau. Os estados sulistas representam $44,4 \%$ da bancada, porém, entre os 18 parlamentares titulares, apenas há representantes do Rio Grande do Sul e do Paraná; o estado de Santa Catarina só tem presença entre os parlamentares suplentes.

Possivelmente, esse fenômeno pode ser explicado pela relevância do Mercosul para os estados mais meridionais. Costa Lima (2006, p. 83) coloca que os estados do eixo sul-sudeste vêem o Mercosul como uma "ampla janela de oportunidades". Nisso, destacam-se os estados da Região Sul, os quais têm a vantagem da proximidade regional dos mercados. Dessa maneira, é natural uma preponderância desses estados nas exportações para o bloco, desde os primeiros tempos de sua existência. Terra e Vaillant (2001) também mencionam o aspecto geográfico da integração, mostrando que as economias regionais presentes nas fronteiras entre os Estados-membros da integração têm acesso facilitado aos mercados. Com relação ao caso do Mercosul, a área fronteiriça mais importante é delimitada pela Região Sul do Brasil, pela República Oriental do Uruguai e pela Região Argentina dos Pampas, onde se encontram as províncias de Buenos Aires, Santa Fé, La Pampa, Córdoba e Entre Rios.

Medeiros (2006) chama a atenção para a atuação de atores políticos e agentes econômicos dos estados de São Paulo e do Rio Grande do Sul com relação à integração "mercosulina". Vigievani (2005) também pontua a ação de atores políticos do governo do Rio Grande do Sul, nesse caso, na atração de investimentos estrangeiros, algumas vezes, segundo uma estratégia dissonante com o governo federal. $\mathrm{O}$ autor ainda aponta a forte relação entre o Codesul ${ }^{19}$ (Mato Grosso do Sul, Paraná, Santa Catarina e Rio Grande do Sul) e a Crecenea $^{20}$ (integrada pelas províncias do Chaco, Corrientes, Entre Rios, Formosa, Missiones e Santa Fé, presentes também na região de fronteira "mercosulina"). Por fim, Wanderley (2002, p. 69) aponta a mobilização de federações de empre-

\footnotetext{
19 Conselho de Desenvolvimento e Integração Sul. Segundo o sítio eletrônico oficial: "O Sistema Conselho de Desenvolvimento e Integração Sul - Banco Regional de Desenvolvimento do Extremo Sul (CODESUL-BRDE) foi criado, em 1961, através de um convênio entre os estados do Rio Grande do Sul, Santa Catarina e Paraná. Em 1992 o estado do Mato Grosso do Sul passou a integrar o Conse1ho. Com o objetivo de encontrar alternativas aos desequilíbrios regionais, com concentração do crescimento no centro do País, o CODESUL constitui-se num foro privilegiado à coordenação e à potencialização em torno de questões comuns aos estados-membros, em especial aquelas relativas ao desenvolvimento econômico e social e à integração ao Mercosul" (CONSELHO DE DESENVOLVIMENTO E INTEGRAÇÃO SUL, 2008).

${ }^{20}$ Comisión Regional de Comercio Exterior del Nordeste Argentino. Segundo o sítio eletrônico oficial: "Fue creada de común acuerdo entre las provincias de Chaco, Corrientes, Entre Ríos, Formosa, Misiones y Santa Fe, con el fin de impulsar la integración del noreste argentino (NEA) con los estados fronterizos vecinos" (COMISIÓN REGIONAL DE COMERCIO EXTERIOR DEL NORDESTE ARGENTINO, 2008).
} 
sários e instâncias de natureza governamental sulistas na inserção regional.

É notável a importância do comércio exterior com o Mercosul para os estados meridionais do Brasil. Apenas para se ter uma idéia disso, entre janeiro de 2006 e janeiro de 2007, no quesito exportação, o Mercosul apresenta o maior peso no Sul, sendo destino de $12,6 \%$ do total exportado pela região; em segundo lugar está a região $\mathrm{Su}-$ deste, com 10,56\%. Na importação, a diferença em relação às outras regiões é ainda maior, 23,03\% do total importado pela região Sul é proveniente do Mercosul. O segundo lugar, bem atrás, é da Região Nordeste, com 11,97\% (BRASIL. MINIS-
TÉRIO DO DESENVOLVIMENTO, INDÚSTRIA E COMÉRCIO EXTERIOR, 2008).

A partir dessa realidade mercantil, surge a hipótese de que o número de cadeiras da bancada brasileira no Parlasul pode apresentar correlação com as exportações estaduais para o bloco. Para testar essa afirmação, primeiramente, é construída uma tabela em que se encontram os estados da federação, com seus respectivos escores brutos em exportação para o Mercosul, e o número de cadeiras na bancada brasileira. A grande maioria dos 27 entes da federação não detém nenhuma cadeira, em parte, devido à bancada encontrar-se resumida a 18 parlamentares.

TABELA 3 - EXPORTAÇÕES PARA O MERCOSUL E NÚMERO DE CADEIRAS NA BANCADA BRASILEIRA DO PARLASUL (POR ESTADO)

\begin{tabular}{|c|c|c|}
\hline ESTADOS DAFEDERAÇÃO & $\begin{array}{l}\text { EXPORTAÇÕES PARA O MERCOSUL } \\
\text { (JAN. } 2006 \text { - JAN. 2007) EM US\$ }\end{array}$ & $\begin{array}{l}\text { CADEIRAS } \\
\text { NABANCADA }\end{array}$ \\
\hline Rio Grande do Sul & 1781102.867 & 6 \\
\hline Paraná & 1356503.070 & 2 \\
\hline Santa Catarina & 605.024177 & 0 \\
\hline São Paulo & 7011048737 & 3 \\
\hline Minas Gerais & 1074878698 & 1 \\
\hline Rio de Janeiro & 722055669 & 0 \\
\hline Espírito Santo & 341061497 & 0 \\
\hline Pernambuco & 92018575 & 0 \\
\hline Bahia & 896598998 & 0 \\
\hline Ceará & 132100332 & 1 \\
\hline Alagoas & 15066934 & 0 \\
\hline Paraíba & 13277632 & 1 \\
\hline Rio Grande do Norte & 12608544 & 0 \\
\hline Sergipe & 7826219 & 0 \\
\hline Piauí & 262005 & 0 \\
\hline Maranhão & 50610528 & 0 \\
\hline Distrito Federal & 375807 & 1 \\
\hline Mato Grosso & 37884808 & 0 \\
\hline Mato Grosso do Sul & 140712946 & 2 \\
\hline Goiás & 44987461 & 0 \\
\hline Acre & 370315 & 1 \\
\hline Amazonas & 313446886 & 0 \\
\hline Pará & 105741012 & 0 \\
\hline Rondônia & 9576696 & 0 \\
\hline Roraima & 250 & 0 \\
\hline Amapá & 48541 & 0 \\
\hline Tocantins & 10822 & 0 \\
\hline Brasil & 14765200026 & 18 \\
\hline
\end{tabular}

FONTE: Os autores, a partir de Brasil. Câmara dos Deputados (2007) e Brasil. Ministério do Desenvolvimento, Indústria e Comércio Exterior (2008). 
Para medir a correlação entre as exportações para o bloco e o número de cadeiras na representação é utilizado o teste de Spearman ${ }^{21}$. Com esse teste estatístico, é possível medir correlações entre distribuições não-normais, o que é o caso dos escores utilizados. Realizado o teste, verifica-se que a correlação fica em 0,423 e a significância mede 0,028 .

A partir dos resultados obtidos, pode-se, primeiramente, por meio da significância (menor do que 0,05) descartar a hipótese nula, ou seja, de que não há correlação. Em seguida, pelo coeficiente de correlação $(0,423)$, pode-se notar que o número de cadeiras por estado e seus respectivos escores brutos de exportações apresentam correlação de grau médio. A sobre-representação histórica dos estados da Região Sul na extinta CPC e, hoje, no Parlasul e sua correlação positiva com as exportações regionais reforçam a tese, colocada pela literatura, de que os estados dessa região apresentam uma maior inserção no processo de integração.

Ainda não se sabe sobre que bases geográficas e forma o escrutínio direto para o Parlasul nos Estados-membros será organizado. Se, por um lado, circunscrições múltiplas ancoradas nas regiões podem servir para dar maior eqüidade à representação cidadã - e.g. as regiões tendo assegurado um número de assentos proporcional a sua população -, por outro, um modo de escrutínio majoritário pode servir para cristalizar a clivagem situação-oposição e, pari passu, facilitar a identificação representante-representado - o que ajudaria o processo de controle do mandato. $\mathrm{O}$ Parlasul, ao adotar o voto direto, terá, assim, condições de corrigir a hipertrofia representativa de algumas unidades subnacionais - mesmo se natural, posto os fluxos mercantis importantes que elas nutrem com o Mercosul e seu inevitável corolário -, tornando-se mais representativo das distintas realidades internas dos seus Estados-membros.

É exatamente procurando refletir as diferenças regionais endógenas próprias a cada um destes Estados-membros que surge a mobilização das unidades infra-estatais. Elas procuram, já há alguns anos, fazer-se representar nas instâncias "mercosulinas".

\footnotetext{
21 Testes estatísticos mais refinados podem ser igualmente utilizados. O teste de Spearman aqui proposto é suficiente apenas para confirmar concretamente um senso comum.
}

\section{O CASO DO FORO CONSULTIVO DE MU- NICÍPIOS, ESTADOS FEDERADOS, PRO- VÍNCIAS E DEPARTAMENTOS DO MERCOSUL (FCCR)}

Nesta seção, busca-se estudar o papel das instituições que pretendem representar as unidades subnacionais em processos de integração regional. Analisa-se o caso do Foro Consultivo de $\mathrm{Mu}-$ nicípios, Estados Federados, Províncias e Departamentos do Mercosul (FCCR), tendo como referencial comparativo o Comitê das Regiões $(\mathrm{CdR})$ da União Européia. A partir de uma perspectiva comparada, será abordado o tema do déficit democrático e do déficit de accountability nas diversas perspectivas estabelecidas pela literatura especializada.

Sobre a criação do FCCR, é válido lembrar que sua origem remonta à Cúpula de Ouro Preto, em dezembro de 2004. Sua instalação, porém, só ocorreu no dia 18 de janeiro de 2007. Ele tem por objetivo criar um novo marco nas relações federativas, tanto no âmbito nacional quanto no regional, inserindo os atores subnacionais na estrutura institucional do Mercado Comum do Sul. O órgão é vinculado ao Grupo Mercado Comum (GMC) (CONSELHO DO MERCADO COMUM, 2004) e se pronuncia por intermédio deste, dentro do âmbito de sua competência, emitindo recomendações, seja por iniciativa própria ou a partir de consultas realizadas pelo GMC e pelos demais órgãos do Mercosul. É composto por dois comitês: um para os municípios; outro, para os estados, províncias e departamentos; cada comitê não pode exceder o número de dez representantes para cada Estado-parte.

O FCCR se reúne de forma ordinária ou extraordinária. As reuniões ordinárias devem ser realizadas, preferencialmente, no Estado-membro sede da Presidência pro tempore, com uma freqüência mínima de uma reunião por semestre, devendo se manifestar por meio de consenso. O Foro Consultivo coordena e orienta as tarefas dos Comitês, considerando suas propostas, que, uma vez adotadas, são encaminhadas ao Conselho do Mercado Comum (CMC) por intermédio do GMC (GRUPO MERCADO COMUM, 2007).

Dada a sua recente constituição, não se pode, ainda, compreender como de fato funciona o Foro Consultivo. Porém, a partir do seu desenho institucional, quando comparado ao do $\mathrm{CdR}$, fica possível inferir algumas projeções de quais serão 
os incentivos e constrangimentos que balizarão as ações dos atores políticos envolvidos. $\mathrm{Na} \mathrm{Ta-}$ bela 4, introduzimos sucintamente um exercício comparativo entre o CdR e o FCCR.

TABELA 4 - QUADRO COMPARATIVO DO DESENHO INSTITUCIONAL DO CDR E DO FCCR

\begin{tabular}{|c|c|c|}
\hline DESENHO INSTITUCIONAL & UNIÃO EUROPÉIA (CDR) & MERCOSUL (FCCR) \\
\hline Objetivo & $\begin{array}{l}\text { Representar os governos } \\
\text { subnacionais }\end{array}$ & $\begin{array}{l}\text { Representar os governos } \\
\text { subnacionais }\end{array}$ \\
\hline Composição & $\begin{array}{l}\text { Representantes eleitos(as) por } \\
\text { sufrágio universal e na vigência } \\
\text { de seu mandato e designado } \\
\text { pelos Estados-partes. Entra em } \\
\text { vigência a partir de } 2003 \text { - } \\
\text { Tratado de Nice }\end{array}$ & $\begin{array}{l}\text { Representantes eleitos(as) por } \\
\text { sufrágio universal e na vigência } \\
\text { de seu mandato e designado } \\
\text { pelos Estados-partes. Entra em } \\
\text { vigência a partir de } 2004 \text { - } \\
\text { Cúpula de Ouro Preto }\end{array}$ \\
\hline Regras de representação & $\begin{array}{l}\text { Cada Estado membro se } \\
\text { encarrega das regras }\end{array}$ & $\begin{array}{l}\text { O FCCR recomenda integrar } \\
\text { ambos os Comitês } \\
\text { considerando a pluralidade } \\
\text { política e a diversidade } \\
\text { demográfica e territorial }\end{array}$ \\
\hline Papel & Consultivo & Consultivo \\
\hline Criação do órgão & Tratado de Maastricht (1992) & Cúpula de Ouro Preto (2004) \\
\hline
\end{tabular}

FONTE: Stuart (2004) e Grupo Mercado Comum (2007)

O principal argumento que sustenta a criação do CdR é o princípio da subsidiariedade, definido no Artigo $5^{\circ}$ do Tratado que institui a Comunidade Européia. Nele, afirma-se que a UE não deve tornar-se um Estado centralizador. Logo, só são repassadas, à União, as tarefas que os Estados-membros não podem realizar satisfatoriamente. Nesse sentido, "o princípio de subsidiariedade pretende assegurar uma tomada de decisões tão próxima quanto possível do cidadão, mediante a verificação constante de que a acção a empreender a nível comunitário se justifica relativamente às possibilidades oferecidas pelo nível nacional, regional ou local. Concretamente, trata-se de um princípio segundo o qual a União só deve actuar quando a sua acção seja mais eficaz do que uma acção desenvolvida a nível nacional, regional ou local excepto quando se trate de domínios da sua competência exclusiva. Este princípio está intimamente relacionado com os princípios da proporcionalidade e da necessidade, que supõem que a acção da União não deve exceder aquilo que seja necessário para alcançar os objectivos do Tratado"(UNIÃO EUROPÉIA, 2008).
No entanto, a consecução do princípio de subsidiariedade padece de problemas na sua efetivação. Assim, quando discutimos sobre a consolidação de instituições subnacionais, encontramos duas questões recorrentes, a saber, o déficit democrático e o poder decisório da instituição. Medeiros (2004) sugere que o CdR possui, por um lado, um input político e, por outro, um output tecnocrático que nem sempre são correspondentes. Ou seja, o Comitê se apresenta como possuindo a capacidade de intervir na rede de poder da UE, mas há barreiras que retardam as respostas, "criando um sistema de retroalimentação lento e pouco efetivo" (MEDEIROS, 2004, p. 166). Já em Stuart (2004) e Medeiros e Vieira (2007), o entrave causador do déficit democrático no Comitê é a sua falta de autonomia em relação aos outros poderes na UE. Tal problema poderia sustentar a visão de Majone (1998), caso o argumento fosse transposto para o nível subnacional. Para ele, o déficit democrático decorre de problemas burocráticos principalmente oriundos da tomada de decisão e da falta de transparência. Contudo, Majone (2001) considera que 
o déficit democrático é atenuado quando se leva em conta o processo nacional de delegação para as instituições supranacionais. Com isso, acredita o autor, diminui-se o custo da tomada de decisão, a partir da autonomia e tecnicidade dessas instituições. Ou seja, o déficit democrático, para Majone (2001), é sinônimo de déficit de credibilidade das instituições européias.

O CdR deseja a ampliação da sua função puramente consultiva e propõe que possa participar da criação normativa da União, levando em consideração os interesses locais e regionais. Seus membros fundamentam esse desejo a partir do já discutido princípio da subsidiariedade, considerando que sua representação ativa reforçaria a legitimidade e a transparência da UE. Essa visão, porém, é contrária à de Majone (2001), que propõe a concentração dos poderes nas mãos da União, a fim de diminuir os problemas decisórios relacionados à delegação de poderes.

Moravcsik (2002) também parte das instituições supranacionais para entender o déficit de-

TABELA 5 - "VOCÊ JÁ OUVIU FALAR DO...?"

\begin{tabular}{|l|c|c|}
\hline ÓRGÃO & SIM & NÃO \\
\hline Comitê das Regiões & $30 \%$ & $62 \%$ \\
Conselho da UE & $63 \%$ & $32 \%$ \\
Banco Central Europeu & $73 \%$ & $24 \%$ \\
Parlamento Europeu & $91 \%$ & $7 \%$ \\
\hline
\end{tabular}

FONTE: Dália (2007).

Ora, vê-se que, embora seu papel precípuo resida em aproximar a tomada de decisão do cidadão - por meio de uma representação mais direta dos interesses locais - o CdR é, por um lado, inexoravelmente menos conhecido do que institutos intergovernamentais como o Conselho da UE - que por sua vez é o órgão principal de tomada de decisão - e, por outro, também menos conhecido do que o Parlamento Europeu, que, além de ser uma instituição bem mais antiga do que o CdR, vem, paulatinamente, adquirindo mais poderes efetivos - nomeadamente o poder de veto no procedimento de codecisão ${ }^{22}$.

Assim, Hix e Follesdal (2006) enfatizam que a possiblidade de contestação política e de participação social no processo decisório geram maior

22 Sobre a codecisão, ver Medeiros e Campos (2007). mocrático. Segundo ele, como já assinalado precedentemente, a natureza não-participativa das instituições européias não significa déficit democrático. Ele acredita que os checks and balances constitucionais, o crescente poder do parlamento e o controle indireto via governos nacionais constituem requisitos suficientes para tornar a política européia transparente e politicamente responsiva frente aos cidadãos europeus. Em contrapartida, Hix e Follesdal (2006) argumentam que a falta de um debate político no cenário supranacional e a inexistência de uma participação mais direta dos cidadãos favorece a apatia e o distanciamento em relação à vida política na UE, sugerindo, indiretamente, a importância do CdR como locus privilegiado para esse debate.

Dália (2007) ressalta que o CdR possui pouca popularidade, apesar da sua vocação de atuar como vetor da subsidiariedade. Ela chama a atenção para o resultado de uma pesquisa realizada em 2000 pelo Instituto Eurobarometer, em que se faz a pergunta: "Você já ouviu falar do...?". O resultado encontra-se abaixo, na Tabela 5. correlação entre as preferências dos representantes frente aos representados. No entanto, não deixam de assinalar que uma democracia mais participativa gera uma perda de eficiência, sendo este o ônus necessário para instituições mais legítimas.

A questão da representação (déficit de accountability vertical) e a falta de poder decisório dentro do sistema de checks and balances são essenciais para se compreender a qualidade democrática e a divisão de poderes no Mercosul. Shugart, Moreno e Crisp (2000) afirmam que accountability é a obrigação dos governantes de informar e explicar seus atos aos eleitores; como também, a capacidade que algumas instituições independentes têm de impor sanções e perda de poder para aqueles que violarem os deveres públicos. Dentro do quadro institucional do Mercado Comum do Sul, até o presente, identifica-se se 
apenas uma accountability vertical indireta, visto que inexiste, stricto sensu, um governo genuinamente supranacional. Também, a accountability horizontal é parcial, pois, diferentemente da UE, em que há uma Corte de Justiça dotada de alta credibilidade e capaz de impor sanções, no Mercosul, o Tribunal de Justiça enfrenta dificuldades para se afirmar como espaço efetivo de resolução de litígios. Inclusive porque as constituições dos Estados-partes ou não reconhecem a supremacia do direito comunitário ou o fazem timidamente baseados num princípio de reciprocidade.

A análise proposta a seguir está baseada em dois momentos. O primeiro visa a discutir a representação (nomeação) como problema que leva ao déficit de accountability. E o segundo procura entender como a falta de poder decisório provoca perda na capacidade de barganha dos interesses subnacionais.

A composição do FCCR é feita a partir de representantes escolhidos de maneira indireta. $\mathrm{Ou}$ seja, um determinado político é indicado para o cargo, sem, portanto, ter sido eleito para ele pelo voto popular direto. Embora, para poder ser indicado, o político necessite deter um mandato eletivo seja no poder Executivo, seja no Legislativo local, como atesta o Art. $2^{\circ}$ do Regimento Interno do FCCR: "El Foro Consultivo estará integrado por representantes electos(as) de Municipios, Estados Federados, Provincias y Departamentos designados(as) por los Estados Partes, integrantes de sus respectivos territorios" (GRUPO MERCADO COMUM, 2007, p. 2).

Esse é também o caso do CdR, o qual, segundo o Art. 263 do Tratado de Nice, estabelece: "A Committee, hereinafter referred to as "the Committee of the Regions', consisting of representatives of regional and local bodies who either hold a regional or local authority electoral mandate or are politically accountable to an elected assembly, is hereby established with advisory status"23 (UNIÃO EUROPÉIA. Comitê das Regiões, 2008).

23 "Um comitê, doravante referido como 'Comitê das Regiões', consistindo de representantes dos corpos regionais e locais que ou detêm um mandato eleitoral regional ou local, ou são politicamente responsáveis perante uma assembléia eleita, é aqui estabelecido com status consultivo" (N.R.).
Visto desse ponto de vista, há um problema de accountability vertical. Neste sistema, não há uma relação institucional direta entre agente (representante) e eleitor (representado). Diz-se que uma relação é vertical quando houver uma hierarquia, ou seja, agentes subordinados e eleitores superiores. Assim, para Shugart, Moreno e Crisp (2000), qualquer relação entre agentes e eleitores que não seja hierárquica não se traduz em relação de accountability. Em poucas palavras, a hierarquia funciona assim: 1) o eleitor delega poder ao agente; 2) o agente é responsivo ao eleitor. Enfim, no FCCR, o controle das autoridades públicas via cidadãos não ocorre diretamente.

No que tange ao poder decisório, como o Foro tem caráter meramente consultivo, não há como os interesses subnacionais se imporem diretamente. O FCCR carece de poder de barganha se comparado ao Conselho do Mercado Comum (CMC), o Grupo Mercado Comum (GMC) ou a Comissão de Comércio (CCM). Contudo, na medida em que as políticas públicas comunitárias podem depender, para sua execução, da capilaridade do poder local, esse poder adquire certa influência. Se as posições do FCCR não são levadas em consideração a montante quando da elaboração de um ato normativo, esse ato poderá sofrer restrições a jusante quando de sua aplicação. Shugart, Moreno e Crisp (2000) analisam a horizontal exchange. Este conceito envolve a existência de partes independentes que controlam umas as outras, porém não por meio de accountability, visto que os órgãos são independentes e, portanto, não são responsáveis uns perante os outros, mas por meio do mecanismo de checks and balances, ou seja, controle e equilíbrio entre agentes. Assim, o que se constata no FCCR é uma quase ausência de controle e equilíbrio, o que gera perda de independência e de poder decisório, devido ao seu caráter consultivo. O FCCR pouco consegue, deste modo, fazer valer suas posições junto às outras instituições do bloco.

Sem embargo, se compara-se o FCCR com as demais instituições "mercosulinas", tomando como parâmetro as variáveis "poder decisório" e "tipo de eleição", constata-se que, tanto do ponto de vista da eficácia quanto do da legitimidade, o FCCR encontra-se em posição pouco privilegiada. O Gráfico 1, abaixo, sugere uma representação esquemática da questão. 
GRÁFICO 1 - PODER DECISÓRIO VERSUS TIPO DE ELEIÇÃO

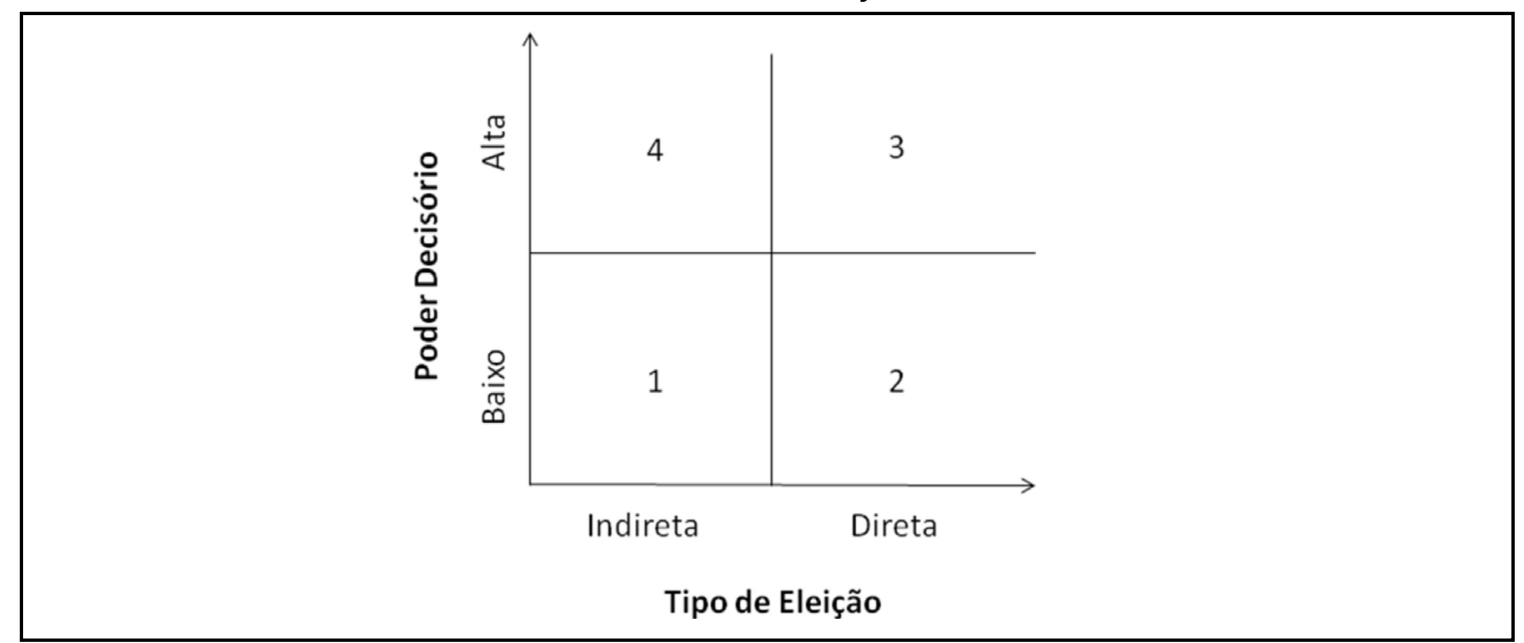

FONTE: Os autores.

A partir da combinação entre a variável "poder decisório" (baixo-alto) e "tipo de eleição" (indireta-direta) são formadas quatro arenas que representam, pari passu, maior ou menor inclusão dos interesses (poder decisório) e grau de legitimidade (tipo de eleição). O cenário imaginado como ideal é aquele em que o órgão tem alto poder decisório e as eleições são diretas, ou seja, o cenário 3. No Mercosul, não há nenhum órgão que se enquadre nestas condições, pois o CMC, o GMC e a CCM, apesar do alto poder decisório que possuem, não estão ancorados numa lógica de representação direta. Eles estão situados no cenário 4. O Parlasul, quando eleito pelo sufrágio direto, estará situado no cenário 2, enquanto o FCCR aliás, como o Foro Consultivo Econômico e Social (FCES) - reúne baixo poder decisório e eleições indiretas e está, portanto, no cenário 1.

Assim, percebe-se que os problemas para a incorporação dos interesses subnacionais na agenda do Mercosul decorrem do desenho institucional do FCCR. Mas, para além do lugar do Foro no seio do Mercado Comum do Sul, ou seja, de como os tomadores de decisão o definem como órgão consultivo e de representação indireta, pode-se observar que a própria prática da "indiretabilidade" não se mostra suficientemente equitável. Isso pode ser constatado por meio das diretrizes que balizam a sua constituição e funcionamento, estabelecidos pelo seu regulamento interno e aprovados por norma (Resolução n. 26/07, do GMC). Segundo o Art. $13 \S 2^{\circ}$ deste regulamento, "la integración de los Comités tendrá en cuenta tanto la pluralidad política como la diversidad demográfica y territorial"'(GRUPO MERCADO COMUM, 2007).
Contudo, por não haver maior clareza no que significa essa recomendação, na prática, encontra-se uma sobre-sub-representação de algumas regiões frente a outras. Por quê? É o que se tenta explicar a partir da análise empírica do caso da representação brasileira no FCCR. Metodologicamente, controla-se a sobre/sub-representação por meio das variáveis "pluralidade política", "diversidade demográfica" e "região geográfica", pois elas são as indicações do Foro para que haja a distribuição dos representantes. Para este estudo, toma-se o FCCR como um todo, ou seja, não se leva em conta sua divisão interna em dois comitês. Considerase a unidade subnacional como podendo ser um município ou um estado, um e/ou outro pertencendo a uma dada região. A principal conseqüência do achado é que a sobre/sub-representação proporciona uma representação - mesmo que limitada ao caráter consultivo do FCCR - desigual dos interesses subnacionais de uma mesma nação.

Vejam-se os dados. Primeiro, mostra-se a distribuição dos assentos a partir da divisão partidária que existe em cada região brasileira. Em cada região, pois, segundo Vicente Trevas, Subchefe de Assuntos Federativos da Secretaria de Relações Institucionais, “[...] cada país terá nove governadores e nove prefeitos ${ }^{24}$. Nós adotamos a

\footnotetext{
24 No caso do Brasil, de acordo com dados da Subchefia de Assuntos Federativos da Secretaria de Relações Institucionais (BRASIL. PRESIDÊNCIA DA REPÚBLICA. SECRETÁRIA DE RELAÇÕES INSTITUCIONAIS, 2008), o comitê de estados tem dez representantes, e o de municípios, oito.
} 
nossa divisão macro regional [...] que terá dois governadores, será o governador do Acre e do Amazonas, e do Nordeste, dois governadores, o de Pernambuco e Bahia. O Sudeste, Espírito Santo e Rio de Janeiro, o Centro-Oeste, Mato Grosso, e o Sul, Rio Grande do Sul e Paraná. [...] Serão nove prefeitos, três [...] nacionais da Frente Nacional de Prefeitos, a Confederação e Associação, depois prefeitos que dirigem a Rede Mercocidades, é o prefeito de Santo André, o de Belo Horizonte, de São Carlos, depois há uma associação de cooperação de municípios, e depois os prefeitos de regiões de fronteira. No Sul, o prefeito de Bagé, e também o prefeito de uma região do Lago de Itaipu, no Paraná" (TREVAS, 2007; sem grifos no original).

Aqui, apresentam-se por região os partidos que governam os estados. Neste caso, o partido político ganharia a vaga ao governar um estado que tem representação no Foro. Em seguida, correlacionase o partido político ao número de assentos que ele obteve no FCCR. Assim, os partidos que possuem maior representação política deveriam obter o maior número de representantes no Foro.

TABELA 6 - PARTIDO POLÍTICO VERSUSASSENTOS NO FCCR, POR REGIÃO GEOGRÁFICA

REGIÃO NORDESTE

\begin{tabular}{|c|c|c|c|}
\hline PARTIDO & $\begin{array}{c}\text { PORCENTAGEM } \\
\text { DE ESTADOS QUE } \\
\text { O PARTIDO } \\
\text { GOVERNA }\end{array}$ & $\begin{array}{c}\text { PORCENTAGEM RELATIVA AO } \\
\text { NÚMERO DE CADEIRAS QUE } \\
\text { O PARTIDO POSSUI NO FORO }\end{array}$ & $\begin{array}{c}\text { STATUS DA } \\
\text { REPRESENTAÇÃO }\end{array}$ \\
\hline PDT & $11,1 \%$ & - & Sem representação \\
PSB & $33,3 \%$ & $50 \%(1)$ & Representação Normal \\
PSDB & $22,2 \%$ & - & Sem representação \\
PT & $33,3 \%$ & $50 \%(1)$ & Representação Normal \\
\hline
\end{tabular}

REGIÃO SUL

\begin{tabular}{|c|c|c|c|}
\hline PARTIDO & $\begin{array}{c}\text { PORCENTAGEM } \\
\text { DE ESTADOS QUE } \\
\text { O PARTIDO } \\
\text { GOVERNA }\end{array}$ & $\begin{array}{c}\text { PORCENTAGEM RELATIVA AO } \\
\text { NÚMERO DE CADEIRAS QUE } \\
\text { O PARTIDO POSSUI NO FORO }\end{array}$ & $\begin{array}{c}\text { STATUS DA } \\
\text { REPRESENTAÇÃO }\end{array}$ \\
\hline PMDB & $66,7 \%$ & $33,3 \%(1)$ & Sub-representado \\
PSDB & $33,3 \%$ & $66,7 \%(2)$ & Sobre-representado \\
\hline
\end{tabular}

REGIÃO CENTRO-OESTE

\begin{tabular}{|c|c|c|c|}
\hline PARTIDO & $\begin{array}{c}\text { PORCENTAGEM } \\
\text { DE ESTADOS QUE } \\
\text { O PARTIDO } \\
\text { GOVERNA }\end{array}$ & $\begin{array}{c}\text { PORCENTAGEM RELATIVA AO } \\
\text { NÚMERO DE CADEIRAS QUE } \\
\text { O PARTIDO POSSUI NO FORO }\end{array}$ & $\begin{array}{c}\text { STATUS DA } \\
\text { REPRESENTAÇÃo }\end{array}$ \\
\hline PFL & $25 \%$ & - & Sem representação \\
PMDB & $25 \%$ & - & Sem representação \\
PP & $25 \%$ & - & Sem representação \\
PPS & $25 \%$ & $100 \%(1)$ & Sobre-representado \\
\hline
\end{tabular}


REGIÃO SUDESTE

\begin{tabular}{|c|c|c|c|}
\hline PARTIDO & $\begin{array}{c}\text { PORCENTAGEM } \\
\text { DE ESTADOS QUE } \\
\text { O PARTIDO } \\
\text { GOVERNA }\end{array}$ & $\begin{array}{c}\text { PORCENTAGEM RELATIVA AO } \\
\text { NÚMERO DE CADEIRAS QUE } \\
\text { O PARTIDO POSSUI NO FORO }\end{array}$ & $\begin{array}{c}\text { STATUS DA } \\
\text { REPRESENTAÇO }\end{array}$ \\
\hline PMDB & $50 \%$ & $40 \%(2)$ & Sub-representado \\
PSDB & $50 \%$ & $60 \%(3)$ & Sobre-representado \\
\hline
\end{tabular}

REGIÃO NORTE

\begin{tabular}{|c|c|c|c|}
\hline PARTIDO & $\begin{array}{c}\text { PORCENTAGEM } \\
\text { DE ESTADOS QUE } \\
\text { O PARTIDO } \\
\text { GOVERNA }\end{array}$ & $\begin{array}{c}\text { PORCENTAGEM RELATIVA AO } \\
\text { NÚMERO DE CADEIRAS QUE } \\
\text { O PARTIDO POSSUI NO FORO }\end{array}$ & $\begin{array}{c}\text { STATUS DA } \\
\text { REPRESENTAÇÃO }\end{array}$ \\
\hline PDT & 14,3 & - & Sem representação \\
PMDB & 28,6 & $33,3 \%(1)$ & Sub-representado \\
PPS & 14,3 & - & Sem representação \\
PSDB & 14,3 & - & Sem representação \\
PT & 28,6 & $66,7 \%(2)$ & Sobre-representado \\
\hline
\end{tabular}

FONTE: Os autores, a partir de Brasil. Presidência da República. Secretária de Relações Institucionais (2008) e Brasil. Tribunal Superior Eleitoral (2008).

NOTA: Siglas partidárias: PDT: Partido Democrático Trabalhista; PFL: Partido da Frente Liberal; PMDB: Partido do Movimento Democrático Brasileiro; PP: Partido Progressista; PPS: Partido Popular Socialista; PSDB: Partido da Social Democracia Brasileira; PSB: Partido Socialista Brasileiro; PT: Partido dos Trabalhadores.

De acordo com a recomendação do FCCR, deve ser respeitada a pluralidade política. Como o Foro não dá informações de como deve se efetivar essa repartição, pode-se interpretar de modo que a distribuição obedeça, por região geográfica, $\mathrm{o}(\mathrm{s})$ partido(s) que obtêm a maioria dos estados sobre o seu comando. Em suma, os partidos que dividem a maioria de estados governados devem ter igual distribuição de assentos no FCCR.

Por essa lógica, a Região Nordeste é a única que possui distribuição equilibrada, pois os partidos que possuem o maior número de estados sob seu controle possuem os dois assentos destinados à região. No caso da Região Sul, o partido que tem a maioria dos estados está sub-representado porque possui a minoria dos assentos no Foro. Com relação à Região Centro-Oeste, cada um dos quatro estados é governado por um partido diferente, e como a região possui apenas um assento no Foro, o estado governado pelo PPS está sobre-representado frente aos outros. Já na Região Sudeste, dois partidos dividem igualmente os governos estaduais, no entanto, o PMDB está subrepresentado frente ao PSDB. Neste caso, como a região divide a força política igualmente entre dois partidos, ambos deveriam possuir o mesmo número de assentos no Foro. Por último, temos o caso da Região Norte. Aqui, tal como na Região Nordeste, dois partidos dividem a maioria dos estados. Contudo, enquanto no Nordeste a divisão corresponde ao cenário político, na Região Norte, o PT está sobre-representado quando comparado ao $\mathrm{PMDB}$.

A partir dessa análise, verifica-se que, ao menos no que se refere à representação subnacional brasileira, a recomendação da pluralidade política não é seguida, visto que os partidos que possuem maior força política nas regiões nem sempre estão proporcionalmente representados no FCCR.

Ainda de acordo com a recomendação do Foro, deve-se respeitar a diversidade demográfica. Entende-se aqui diversidade demográfica como sendo o tamanho da população, neste caso, de cada região. Para averiguar se há ou não problema de representação, relaciona-se o número de assentos que cada região possui com a população total de cada uma delas. Ao se dividir o número total de assentos pelo da população total, encontramos o 
escore: $7,60 \times 10^{-8}$. Esse valor balizará nossa análise, visto que, proporcionalmente, a divisão deveria respeitar o critério de 1 representante para cada 13141950 habitantes. Vejamos a tabela e a figura que seguem, em que os números não estão em escala real.

TABELA7 - NÚMERO DE ASSENTOS VERSUS POPULAÇÃO.

\begin{tabular}{|c|c|c|c|c|}
\hline REGIÃOBRASILEIRA & $\begin{array}{l}\text { NÚMERO } \\
\text { DE ACENTOS } \\
\text { NOFCCR }\end{array}$ & $\begin{array}{l}\text { POPULAÇÃO } \\
\text { (POP) }\end{array}$ & $\begin{array}{c}\text { COEFICIENTEDE } \\
\text { REPRESENTAÇÃO } \\
\text { X } 10^{-8} \\
\text { (No ASSENTO/POP) }\end{array}$ & $\begin{array}{c}\text { VALOR } \\
\text { ESPERADO }\end{array}$ \\
\hline Região Centro-Oeste (CO) & 1 & 13222854 & 7,56 & 1,00 \\
\hline Região Norte $(\mathrm{N})$ & 3 & 14623316 & 20,5 & 1,11 \\
\hline Região Sul (S) & 3 & 26733595 & 11,2 & 2,03 \\
\hline Região Nordeste (NE) & 2 & 51534406 & 3,88 & 3,92 \\
\hline Região Sudeste (SE) & 5 & 77873120 & 6,42 & 5,92 \\
\hline Total & 14 & 183987291 & 7,60 & 14 \\
\hline
\end{tabular}

FONTE: Os autores, a partir de Instituto Brasileiro de Geografia e Estatística (2004) e Brasil. Presidência da República. Secretária de Relações Institucionais (2008).

NOTA: O total é 18, e não 14, pois há quatro assentos no comitê de municípios que estão atribuídos a órgãos representativos, a saber: Conselho de Desenvolvimento dos Municípios Lindeiros do Lago de Itaipu, Frente Nacional de Prefeitos, Associação Brasileira de Municípios e Confederação Nacional de Municípios. No entanto, só estamos levando em consideração as representações estaduais e municipais.

FIGURA 1 - ESCALADE SUB/SOBRE-REPRESENTAÇÃO

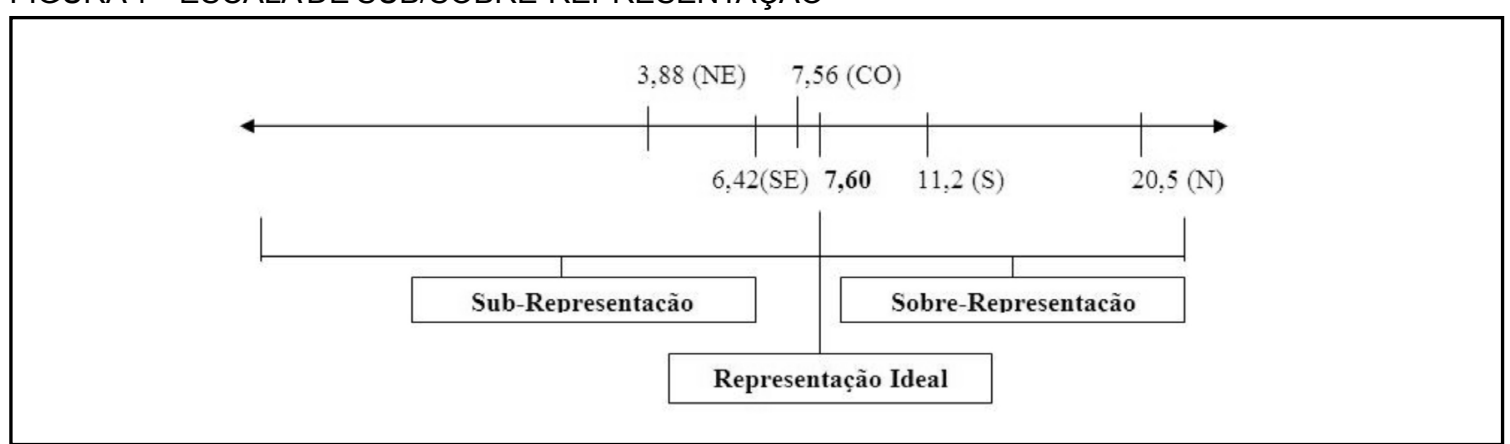

FONTE: Os autores.

A partir disso, podemos dizer que, tendo como referencial a população, os problemas relacionados à sub-sobre-representação persistem. Rigorosamente, as Regiões Centro-Oeste, Sudeste e Nordeste estão sub-representadas pelo critério populacional. No entanto, a discrepância maior acontece com a região Nordeste e menos com a Sudeste e a Centro-Oeste. A região Centro-Oeste, em termos práticos, possui o número de representantes proporcional a sua população. Em lado oposto, encontramos as regiões que estão sobrerepresentadas. Nesse caso, figuram a região Sul e Norte, cada uma com três representantes, quando na verdade deveriam ter 2,03 e 1,11, respectivamente. Assim, podemos dizer que também não é respeitado o critério da diversidade populacional para a alocação dos representantes.

Por fim, o último critério elencado é a diversidade territorial. Uma forma de tornar a distribuição de assentos eqüitativa é controlando a alocação de cadeiras pelo número de estados que cada região possui. Então, para a região Sul, que possui três estados, seriam destinados três representantes, e assim por diante. Deste modo, o valor esperado na representação territorial seria 1 para todos, acima de 1 caracterizando a sobre-representação, e o inverso, a sub-representação. No entanto, como pode ser percebido na Tabela 8, com exceção da Região Sul, todas as outras regiões estão sobre ou sub-representadas. 
TABELA 8 - REPRESENTAÇÃO POR NÚMERO DE ESTADOS

\begin{tabular}{|l|c|c|c|}
\hline REGIÃOBRASILEIRA & $\begin{array}{c}\text { NÚMERODE } \\
\text { ASSENTOS } \\
\text { NOFCCR }\end{array}$ & $\begin{array}{c}\text { NÚMERODE } \\
\text { ESTADOS } \\
\text { POR REGIÃO }\end{array}$ & $\begin{array}{c}\text { REPRESENTAÇÃO PROPORCIONAL } \\
\text { POR NÚMERO DE ESTADOS } \\
\text { EM CADA REGIÃO }\end{array}$ \\
\hline Região Sudeste & 5 & 4 & $5 / 4=1,25$ \\
Região Sul & 3 & 3 & $3 / 3=1$ \\
Região Norte & 3 & 7 & $3 / 7=0,42$ \\
Região Centro-Oeste & 1 & 4 & $1 / 4=0,25$ \\
Região Nordeste & 2 & 9 & $2 / 9=0,22$ \\
\hline
\end{tabular}

Fonte: Os autores, a partir de Instituto Brasileiro de Geografia e Estatística (2004) e Brasil. Presidência da República. Secretária de Relações Institucionais (2008).

No gráfico tipo pizza que está associado à distribuição dos assentos no FCCR, pode-se verifi- car a fatia que pertence a cada região atualmente, inclusive em porcentagem.

\section{GRÁFICO 2-DISTRIBUIÇÃO DOS ASSENTOS POR REGIÕES}

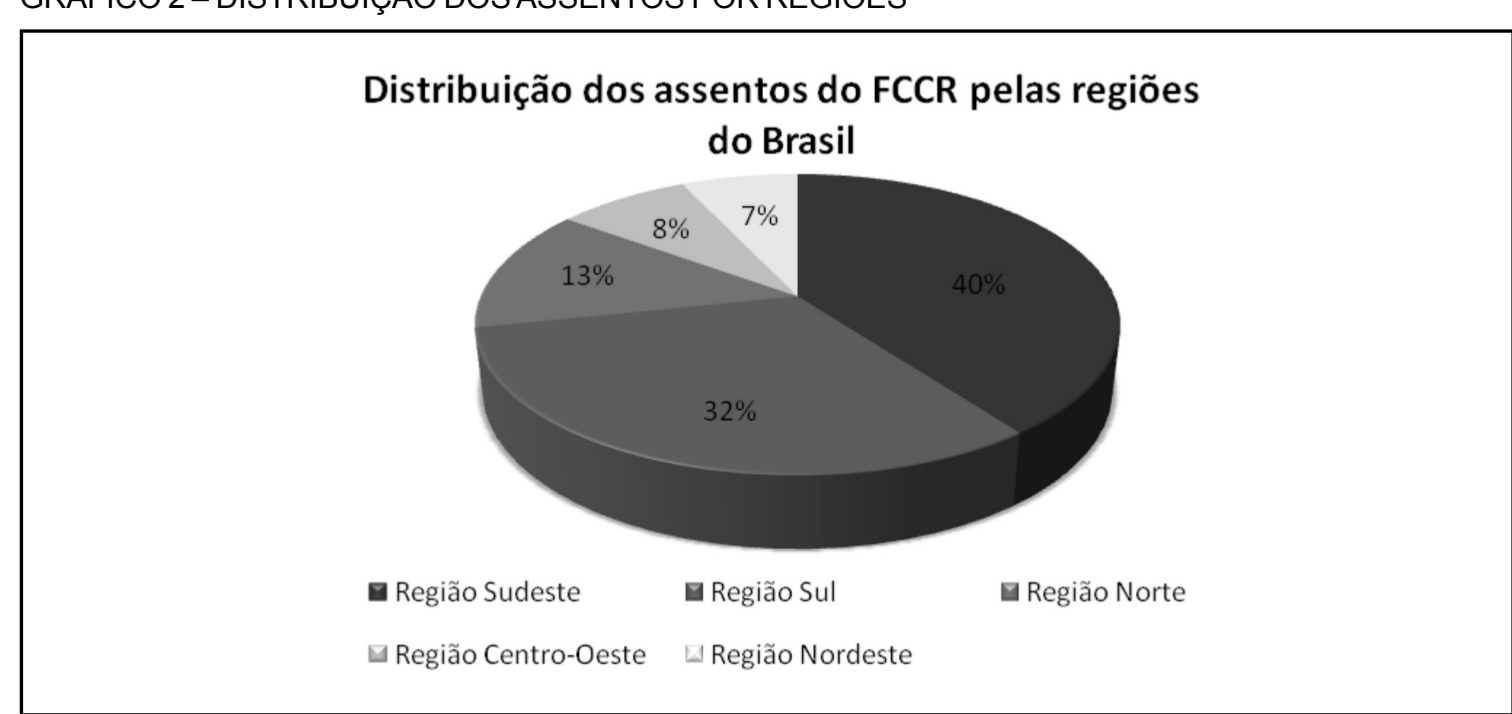

Após apresentar apenas a distribuição das cadeiras no Foro Consultivo, mostra-se o teste estatístico que corrobora a desigualdade da repartição mostrada anteriormente ${ }^{25}$. Logo, comparando a média do número de assentos por região brasileira, temos que há uma sobre-representação estatisticamente significante no número de representantes quando feito um corte por região. Para significância (sig.) menor ou igual a 0,05 , corrobora-se a hipótese que afirma haver diferença de médias.

TABELA 9 - ANÁLISE DE VARIÂNCIA(ANOVA)

\begin{tabular}{|l|c|c|c|c|c|}
\hline \multicolumn{1}{|l|}{ NÚMERO DE CADEIRAS NO FORO CONSULTIVO } & \multicolumn{3}{l|}{ Sig. } \\
\hline & SOMA DOS QUADRADOS & $\mathrm{df}$ & QUADRADO MÉDIO & $\mathrm{F}$ & 0,032 \\
\hline Entregrupos & 3,971 & 4 & 0,993 & 3,226 & \\
No interior dos grupos & 6,770 & 22 & 0,308 & & \\
Total & 10,741 & 26 & & & \\
\hline
\end{tabular}

25 A análise de variância (ANOVA) é um método para testar a igualdade de três ou mais médias populacionais, baseado na análise de variâncias amostrais. Utiliza-se a ANOVA em aplicações como: Quando Kaplan, Princeton
Review e Collins Test Prep ministram cursos preparatórios diferentes para os testes SAT, podemos testar se há diferenças nos escores SAT médios para as três populações de estudantes provenientes dos três cursos distintos (TRIOLA, 1999, p. 282). 
Por fim, é válido salientar que as instituições não necessariamente funcionam como pretendem, mas elas são fundamentais para estabelecer accountability, e sem instituições formais desenhadas a accountability efetiva é impossível (MAINWARING, 2003). Neste caso específico, mostramos que um marco normativo pouco explícito provoca um sistema em que algumas regiões estão sub ou sobre-representadas. E, mais do que isso, ocasiona também um descumprimento das recomendações que o Foro faz para a indicação dos representantes. Como vimos, a relação entre "tipo de eleição", ou seja, o tipo de controle exercido pelo representado/representante, o "poder de barganha" de uma instituição frente a outras e o "desenho institucional" interferem diretamente na forma como interesses - nesse caso, subnacionais - figuram no ambiente institucional.

\section{CONCLUSÕES}

A questão da representação nas ORIs, em geral, e no Mercosul, em particular, se revela por demais complexa. Sem poder renegar as origens "estatocêntricas" da Teoria Democrática, que durante séculos articulou os arranjos políticos da humanidade, percebe-se que a mesma enfrenta dificuldades para explicar o funcionamento do governo em múltiplos níveis, tal qual o existente no seio da UE. O processo mimético é inevitável, tanto no sentido "modelo clássico de Westminster ORI", quanto no sentido "União Européia - ou- tras ORIs" (COSTA \& MAGNETTE, 2003), aí incluído o Mercado Comum do Sul (DRI, 2008). O debate sobre o déficit democrático extrapola as fronteiras do Estado-nação, em que os exercícios comparativos sobre formas de governo nunca cessaram de existir. Ele permeia, mais recentemente, os meandros das ORIs, dado que o nível de integração de algumas delas revela-se consistente, tendo implicações relevantes para o cidadão.

O Mercado Comum do Sul resta uma estrutura eminentemente intergovernamental e, nesse sentido, muito diferente da União Européia. Mas o Mercosul resta, igualmente, um empreendimento não apenas comercial e, nesse sentido, muito diferente do North America Free Trade Agreement (Nafta). A mobilização das sociedades civis dos Estados-partes, o aumento da interdependência econômica entre eles, a consciência da inevitabilidade da inserção internacional, assim como a consolidação democrática de seus sistemas políticos faz com que os membros do Mercado Comum do Sul executem alguns mecanismos de controle. Isso passa pela instauração do Parlasul, como também pela criação do FCCR. Apesar dos papéis essencialmente consultivos dessas duas instâncias e de suas imperfeições no que concerne à prática da representação e do controle, elas se constituem em elementos concretos que podem, ou não, gerar momentum para novas invenções políticas.

Marcelo de Almeida Medeiros (mam14@pq.cnpq.br) é Doutor em Ciência Política pelo Institut d’Études Politiques de Grenoble (França) e Professor da Universidade Federal de Pernambuco (UFPE).

Natália Leitão (natalialeitao@gmail.com) é Graduada em Ciências Sociais pela Universidade Federal de Pernambuco (UFPE).

Henrique Sérgio Cavalcanti (h_sbcj@yahoo.com.br) é Graduando em Ciências Sociais pela Universidade Federal de Pernambuco (UFPE).

Maria Eduarda Paiva (mariaeduardapaiva@gmail.com) é Graduanda em Direito pela Universidade Federal de Pernambuco (UFPE) e bolsista da Fundação de Amparo à Ciência e Tecnologia do Estado de Pernambuco (Facepe) no Programa Institucional de Bolsas de Iniciação Científica (Pibic) da UFPE.

Rodrigo Santiago (rodrigosantiago_18@hotmail.com) é Graduando em Ciências Sociais pela Universidade Federal de Pernambuco (UFPE). 


\section{REFERÊNCIAS BIBLIOGRÁFICAS}

ALMEIDA, P. 1998. Mercosul: fundamentos e perspectivas. São Paulo: LTR.

CAETANO, G. \& ANTÓN, R. 2001. La consolidación institucional del Mercosur: el rol de los parlamentos. In: SIERRA, G. (org.). Los Rostros del Mercosur: el difícil camino de lo comercial a lo societal. Buenos Aires: CLACSO.

CAREY, J. \& REINHARDT, G. 2003. Impacto das instituições estaduais na unidade das coalizões parlamentares no Brasil. Dados, Rio de Janeiro, v. 46, n. 4, p. 773-804. Disponível em: http://www.scielo.br/scielo.php?pid $=\mathrm{S} 0011-52582003000400005 \&$ script $=$ sci arttext\&tlng=pt. Acesso em: 1.set.2010.

COSTA LIMA, M. 2001. A dinâmica espacial do Mercosul: assimetrias em regiões brasileiras. In: SIERRA, G. (org.). Los Rostros del Mercosur: El difícil camino de lo comercial a lo societal. Buenos Aires: CLACSO.

COSTA, O. \& MAGNETTE, P. 2003. Idéologies et changement institutionel dans l'Union européenne: porquoi les gouvernements ontils constamment renforcé le Parlament européen? Politique Européenne, Paris, n. 9, p. 49-75.

COSTA, S. \& WERLE, D. L. 2006. Unificação desigual. Entrevista com Hauke Brunkhorst. São Paulo: CEBRAP.

DAHL, R. 1994. Democratic Dilemma: System Effectiveness versus Citizen Participation. Political Science Quarterly, v. 109, n. 1. Disponível em: http://top10headline.com/ attachments/351_Academic\%20paper.pdf. Acesso em: 1.set.2010.

DÁLIA, J. 2007. O déficit democrático na União Européia: o papel do Comitê das Regiões e o mecanismo de accountability no processo de tomada de decisões. Recife. Dissertação (Mestrado em Ciência Política). Universidade Federal de Pernambuco.

DELORS, J. 1989. Discours du 17 octobre 1989, lors de l'ouverture solennelle de la 40ème année académique du Collège d'Europe de Bruges. Bull.CE, v. 10, n. 89, p. 123-126.

DEUTSCH, K. 1954. Political Community at the Interantional Level. New York: Doubleday.
1957. Political Community and the North Atlantic Area. New Jersey: Princeton University.

DINIZ, E. 1992. Governabilidade, democracia e reforma do Estado: os desafios da construção de uma nova ordem no Brasil dos anos 90. In: DINIZ, E. \& AZEVEDO, S. (orgs.). Reforma do Estado e democracia no Brasil: dilemas e perspectivas. Brasília: UNB.

DRI, C. 2008. The Mercosur Parliament: Democracy and Integration on European Patterns? III GARNET Annual Conference, Bordeaux, September.

ELIAS, N. 1997. Os alemães. Rio de Janeiro: J. Zahar.

FELD, W. \& WILDGEN, J. 1975. Electoral Ambitions and European Integration. International Organization, Cambridge, UK, v. 29, n. 2, p. 447-468.

FOLLESDAL, A. \& HIX, S. 2006. Why There Is A Democratic Deficit In The EU: A Response To Majone And Moravcsik. Journal of Common Market Studies, Oxford, v. 44, n. 3, p. 533-562.

GENEYRO, R. \& VÁZQUEZ, M. 2006. La ampliación de la agenda política y social para el Mercosur actual. Aldea Mundo, San Cristobal, v. 11, n. 20, p. 7-18. Disponível em: http:/www.saber.ula.ve/bitstream/123456789/ 18216/2/articulo1.pdf. Acesso em: 1.set.2010.

HAAS, E. 2004. The Uniting of Europe: Political, Social, and Economic Forces, 1950-1957. Indiana: University of Notre Dame.

HABERMAS, J. 2003. Mudança estrutural da esfera pública: investigações quanto a uma categoria da sociedade burguesa. Rio de Janeiro: Tempo Brasileiro.

HELD, D. 1996. Models of Democracy. Stanford: Stanford University.

HIX, S.; NOURY, A. \& ROLAND, G. 2006. Dimensions of Politics in the European Parliament. American Journal of Political Science, Dallas, v. 50, n. 2, p. 494-511.

HIX, S.; RAUNIO, T. \& SCULLY, R. 2003. Fifty Years on: Research on the European Parliament. 
Journal of Common Market Studies, Oxford, v. 41, n. 2, p. 191-202.

HOBBES, T. 1651. Leviathan or the Matter, Forme, and Power of a Commonwealth Ecclesiastical and Civil. Disponível em: socserv.mcmaster.ca/econ/ugcm/3113/hobbes/ Leviathan.pdf. Acesso em: 20.mai.2008.

JEHAN, A. 2007. La culture au sein de l'Union européenne: objet politique non identifié. Collection Euryopa, Genève, v. 54, p. 21.

LIPSET, S. 1967. O homem politico. Rio de Janeiro: Zahar.

MAINWARING. S. \& WELNA, C. 2003. Democratic Accountability in Latin America. Oxford: Oxford University.

MAJONE, G. 1998. Europe's Democratic Déficit: The Question of Standards. European Law Journal, Oxford, v. 4, n. 1, p. 5-28.

.2006. Légitimer l'UE par la participation et la délibération? . Notre Europe, Paris, 12.out. Disponível em: http://www.notre-europe.eu/fr/ ils-reagissent/contributions/publication/ reaction-de-giandomenico-majone-au-textedandrew-moravcsik/. Acesso em: 1.set.2010.

2001. Two Logics of Delegation: Agency and Fiduciary Relations in EU Governance. European Union Politics, London, 2, 1, p. 103122.

MALAMUD, A. \& SOUZA, L. 2005. Parlamentos supranacionais na Europa e na América Latina: entre o fortalecimento e a irrelevância. Contexto Internacional, Rio de Janeiro, v. 27, n. 2, p. 369-409. Disponível em: http:// www.scielo.br/scielo.php?pid=S0102$85292005000200005 \&$ script $=$ sci_arttext. Acesso em: 1.set.2010.

MEDEIROS, M. 2000. La genèse du Mercosud. Paris: L'Harmattan.

2003. Prerrogativas estatais, integração regional e lógica distributiva. Lua Nova, São Paulo, n. 58, p. 141-168. Disponível em: http:/ /www.scielo.br/scielo.php?script= sci_arttext\&pid=S0102-64452003000100008. Acesso em: 1.set.2010.

. 2004. Unidades subnacionais e integração européia: o caso do comitê de regiões. In: VIGEVANI, T.; WANDERLEY, L.; BARRETO,
M. \& MARIANO, M. (orgs.). A dimensão subnacional e as relações internacionais. São Paulo: UNESP.

.2006. Dinâmica subnacional e lógica centro-perifeira: os impactos do Mercosul na economia política dos estados de Pernambuco, Bahia, São Paulo e Rio Grande do Sul. Revista Brasileira de Política Internacional, Brasília, v. 49, n. 1, p. 43-67. Disponível em: http:// www.scielo.br/scielo.php?pid=S0034$73292006000100003 \&$ script $=$ sci_arttext\&tlng $=$ pt. Acesso em: 1.set.2010.

MEDEIROS, M. \& AIRES, A. V. 2007. Lógicas de centro versus dinâmica de margens: a questão subnacional na União Européia. Contexto Internacional, Rio de Janeiro, v. 29, n. 2, p. 363-392. Disponível em: http:/www.scielo.br/ scielo.php?script $=$ sci_arttext\&pid $=$ S010285292007000200004 . Acesso em: 1.set.2010.

MEDEIROS, M. \& CAMPOS, C. R. 2007. União Européia, reformas institucionais e déficit democrático: uma análise a partir do mecanismo de co-decisão. XXXI Encontro Anual da Associação Nacional de Pós-Graduação em Ciências Sociais, Caxambú.

MORAVCSIK, A. 2002. Defence of the Democratic Deficit: Reassessing Legitimacy in the European Union. Journal of Common Market Studies, Oxford, v. 40, n. 4, p. 603624.

MURRAY, P. 2004. Factors for Integration? Transnational Party Cooperation in the European Parliament, 1952-1979. Australian Journal of Politics and History, Brisbane, v. 50, n. 1, p. 102-115.

O'DONNELL, G. 2004. Accountability horizontal: la institucionalización legal de la desconfianza política. Revista Española de Ciencia Política, Madrid, n. 11, p. 11-31. Disponível em: http://www.aecpa.es/archivos/ publicaciones/recp/11/textos/01.pdf. Acesso em: 1.set.2010.

RITTBERGER, B. 2003. The Creation and Empowerment of the European Parliament. Journal of Common Market Studies, Oxford, v. 41, n. 2, p. 203-224.

SCHARPF, F. W. 2006. The Joint-Decision Trap Revisited. Journal of Common Market Studies, Oxford, v. 44, n. 4, p. 845-864. 
SCHMITTER, P. 2000. How to Democratize the European Union... And Why Bother? New York: Rowman \& Littlefield.

SHUGART, M. S.; MORENO, E. \& CRISP, B. 2000. The Accountability Deficit in Latin America. Institutions, Accountability, and Democratic Governance in Latin America, University of Notre Dame, Notre Dame, Inglaterra, maio.

SCHUMPETER, J. 1975. Capitalism, Socialism and Democracy. Nova York: Harper Collins.

SOUZA, C. 1998. Intermediação de interesses regionais no Brasil: o impacto do federalismo e da descentralização. Dados, Rio de Janeiro, v. 41, n. 3. Disponível em: http://www.scielo.br/ s c i e 1 o.p h p ? p i d = S 00011 2581998000300003\&script=sci_arttext. Acesso em: 9.jan.2008.

STUART, A. M. 2004. Regionalismo e democracia: o surgimento da dimensão subnacional na União Européia. In: VIGEVANI, T.; WANDERLEY, L.; BARRETO, M. I. \& MARIANO, M. (orgs.) A dimensão subnacional e as relações internacionais. São Paulo: UNESP.

TERRA, I. \& VAILLANT, M. 2001. Comercio, fronteras políticas y geografía: un enfoque regional de la integración econômica. In: SIERRA, G. (org.). Los rostros del Mercosur: el difícil camino de lo comercial a lo societal. Buenos Aires: CLACSO.
TOSTES, A. P. 2006. Por que não uma Constituição européia? Dados, Rio de Janeiro, v. 49, n. 2, p. 379-415. Disponível em: http:// w $\quad$ w $\quad$ w scielo.php?script $=$ sci_arttext\&pid $=\mathrm{S} 0011$ 52582006000200005. Acesso em: 1.set.2010.

TRIOLA, M. F. 1999. Introdução à Estatística. Rio de Janeiro: LTC.

VIGEVANI, T. 2005. Problems for international activity of sub-national units: the brazilian case. First Global International Studies Conference, World International Studies Committee (WISC), Istambul, agosto.

VIGEVANI, T.; OLIVEIRA, M. \& MARIANO, K. 2000. Democracia e atores políticos no Mercosul. In: MEDEIROS, M. \& COSTA LIMA, M. (orgs.). Mercosul no limiar do século XXI. São Paulo: Cortez.

VILLA, R. D. \& TOSTES, A. P. 2008. Democracia cosmopolita versus política internacional. Lua Nova, São Paulo, n. 66, p. 69-107. Disponível em: http://www.scielo.br/ s c i e 1 o.p h p ? p i d = S 01002 $64452006000100005 \&$ script $=$ sci_arttext. Acesso em: 1.set.2010.

WANDERLEY, L. E. 2002. Mercosul e sociedade civil. São Paulo em Perspectiva, São Paulo, v. 16, n. 1, p. 63-73. Disponível em: http:/ /www.scielo.br/scielo.php?pid=S0102$88392002000100008 \&$ script $=$ sci_arttext. Acesso em: 1.set.2010.

\section{OUTRAS FONTES}

BRASIL. Câmara dos Deputados. 2007. Composição da bancada brasileira no Parlasul. Disponível em: http:/www2.camara.gov.br/ comissoes/cpcms/composicao/brasil.html . Acesso em: 1.out.2007.

BRASIL. Ministério do Desenvolvimento, Indústria e Comércio Exterior. 2008. Sítio eletrônico. Disponível em: http:// www.desenvolvimento.gov.br/sitio/. Acesso em: 12.set.2008.

BRASIL. Presidência da República. Secretaria de Relações Institucionais. 2008. Sítio eletrônico. Disponível em: http://www.planalto.gov.br/ sri/foro_consultivo/estrutura.html. Acesso em: 22.set. 2008 .
BRASIL. Tribunal Superior Eleitoral. 2008. Sítio eletrônico. Disponível em: http:// www.tse.jus.br/internet/index.html. Acesso em: 22.set.2008

\section{COMISIÓN REGIONAL DE COMERCIO} EXTERIOR DEL NORDESTE ARGENTINO. 2008. Sítio eletrônico. Disponível em: http://www.crecenea.org.ar/index.html. Acesso em: 12.set.2008.

\section{COMISSÃO EUROPÉIA. 1999. Eurobarometer} Disponível em: http://ec.europa.eu/ public_opinion/index_en.htm. Acesso em: 12.set.2008. 
CONSELHO DE DESENVOLVIMENTO E INTEGRAÇÃ̃ SUL. 2008. Sítio eletrônico. Disponível em: http://www.codesul.com.br/. Acesso em: 12.set.2008.

CONSELHO DO MERCADO COMUM. 2004. Decisão 41/04. Montevidéu.

2005. Protocolo Constitutivo do Parlamento do Mercosul. Decisão n. 23/05. Montevidéu, 8.dez.

GRUPO MERCADO COMUM. 2007. Regulamento Interno do Foro Consultivo de Municipios, Estados Federados, Províncias e Departamentos do Mercosul. Montevidéu, 27.set. Disponível em: http://www.mercosur.int/msweb/ Normas/normas_web/Resoluciones/PT/2007/ RES_026-2007_PT_Reglamento\%20Interno\% 20FCCR.doc. Acesso em: 28.mai.2008.

INSTITUTO BRASILEIRO DE GEOGRAFIA E ESTATÍSTICA. 2004. Disponível em: http:/ /www.ibge.gov.br/home/. Acesso em: 1.set.2010.
INSTITUTO NACIONAL DE ESTADÍSTICAY CENSOS. 2007. Disponível em: http:// www.indec.mecon.ar/. Acesso em: 1.set.2010.

PARLAMENTO DO MERCOSUL. 2007. Regimento Interno. Disponível em: http:// www2.camara.gov.br/comissoes/cpcms/ parlamentoMercosul.html. Acesso em: 1.set.2010.

UNIÃo EUROPÉIA. 2008. Verbete "Subsidiariedade". Europa: o portal oficial da União Européia. Glossário. Disponível em: http://europa.eu/scadplus/glossary/ subsidiarity_pt.htm. Acesso em: 15.set.

UNIÃO EUROPÉIA. Comitê das Regiões. 2008. Sítio eletrônico. Disponível em: http:// www.cor.europa.eu/pages/Presentation Template. aspx ?view $=$ folder\&id $=90178593$ c 7 ed - 4 e $16-822$ f-a e 06 c 1453 c 22 \& $\mathrm{sm}=90178593-\mathrm{c} 7 \mathrm{ed}-4 \mathrm{e} 16-822 \mathrm{f}-\mathrm{ae} 06 \mathrm{c} 1453 \mathrm{c}$ 22. Acesso em: 16.set. 
THE ISSUE OF REPRESENTATION WITHIN THE MERCOSUR: PARLASUR AND FCCR AS CASE STUDIES

Marcelo de Almeida Medeiros, Natália Leitão, Henrique Sérgio Cavalcanti, Maria Eduarda Paiva and Rodrigo Santiago

One of the problems that has attracted the greatest attention of scholars who study Regional International Organizations is the issue of representation. The institutional arrangements that have been built up within these organizations have sought to reflect representation in its twofold expression, in other words, as an assembly of member-states and another that is made up of citizens' delegates. However, some arrangements have innovated by creating forums made up of sub-national entities, thus seeking to attenuate what certain authors have referred to as the "democracy deficit". Our objectives here are to scrutinize the constitutive dynamics of two Southern Common Market organs of representation: (i) the Mercosur Parliament (Parlasur) and (ii) the Constitutive Forum of Municipalities, Federate States, Provinces and Departments of the Southern Common Market (Foro Consultivo de Municípios, Estados Federados, Províncias e Departamentos do Mercosul (FCCR). We attempt to identify the parameters that provide support for their respective compositions and, from there, go on to reflect on the issue of representation. We come to the conclusion that, notwithstanding the essentially consultative roles of Parlasur and the FCCR and their imperfections regarding practices of representation and control, they nonetheless become concrete elements that may or may not create momentum for new political inventions.

KEYWORDS: Southern Common Market; representation; Parliament; para-diplomacy; regionalism. 


\section{LA QUESTION DE LA REPRESENTATION AU MERCOSUR : LES CAS DU PARLASUL ET DU FCCR}

Marcelo de Almeida Medeiros, Natália Leitão, Henrique Sérgio Cavalcanti, Maria Eduarda Paiva et Rodrigo Santiago

Un des problèmes qui attire le plus l'attention des chercheurs des organisations régionales internationales (ORI), c'est celui de la représentation. Les arrangements institutionnels construits sur eux, cherchent à tenir compte de cette représentation dans sa double ramification, à savoir : une assemblée constituée par les états-membres ; une autre formée par des délégués des citoyens. Quelques uns d'eux, toutefois, innovent par la création de forums composés par des êtres infranationaux, cherchant atténuer ce que certains auteurs appellent "déficit démocratique". L'objectifs de ce travail sont d'observer la dynamique constitutive de deux organes de représentation du "Marché Commun du Sud": (i) le Parlement du Mercosur (Parlasul) ; (ii) le Forum Consultatif de Villes, Etats Fédérés, Provinces et Départements du Mercosul (FCCR). On cherche à identifier les paramètres qui tracent leurs compositions respectives et à partir de là, on essaye de penser sur la question de la représentation. La conclusion c'est que, malgré les rôles essentiellement consultatifs du Parlasul et du FCCR et de leurs imperfections à l'égard de la pratique de la représentation et du contrôle, elles se constituent en éléments concrets qui peuvent, ou ne peuvent pas, générer momentum pour des nouvelles inventions politiques.

MOTS-CLES : Mercosur ; représentation, Parlement ; paradiplomatie ; régionalisme. 